ERNEST GRLANDO LAWRENGE

BERKELEY NATIONAL LAEDRATIRY

\title{
Diagnostics for Building \\ Commissioning and Operation
}

Anthony Sebald and Mary Ann Piette

Environmental Energy

Technologies Division

MASTER RECEIVED

December 1997

MAY $O 8998$

DISTRIEUTION OF THHS DOCURENT IS UNUMITED ph

OSTI

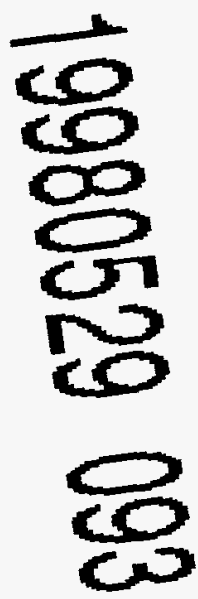

DTLQ QUATITY TNOPECIED 1 


\section{DISCLAIMER}

While this document is believed to contain correct information, neither the United States Department of Energy (DOE) nor any agency thereof, nor The Regents of the University of California (The Regents), nor the California Institute for Energy Efficiency (CIEE), nor any of CIEE's sponsors or supporters (including California electric and gas utilities), nor any of these organizations' employees, make any warranty, express or implied, or assume any legal liability or responsibility for the accuracy, completeness, or usefulness of any information, apparatus, product, or process disclosed, or represent that its use would not infringe privately owned rights. Reference herein to any specific commercial product, process, or service by its trade name, trademark, manufacturer, or otherwise, does not necessarily constitute or imply its endorsement, recommendation, or favoring by DOE or any agency thereof, or The Regents, or CIEE, or any of CIEE's sponsors or supporters. The views and opinions of authors expressed herein do not necessarily state or reflect those of DOE or of any agency thereof, of The Regents, of CIEE, or any of CIEE's sponsors or supporters, and the names of any such organizations or their employees shall not be used for advertising or product endorsement purposes.

This report has been reproduced directly from the best available copy

Available to DOE and DOE Contractors

from the Office of Scientific and Technical Information

P.O. Box 62, Oak Ridge, TN 37831

Prices available from (615) 576-8401

Available to the public from the

National Technical Information Service

U.S. Department of Commerce

5285 Port Royal Road, Springfield, VA 22161

Ernest Orlando Lawrence Berkeley National Laboratory is an equal opportunity employer. 
LBNL-40512

\title{
Diagnostics for Building Commissioning and Operation
}

\section{December 1,1997}

\author{
Anthony Sebald (University of California San Diego) \\ and Mary Ánn Piette (Lawrence Berkeley National Laboratory)
}

Additional Research Team Members:

K. Heinemeier (currently with Honeywell, formerly with LBNL), Lee Eng Lock (SuperSymmetry), H. Misuriello, D. Seborg (Univ. Calif. Santa Barbara) and C. Shockman (Stanford University)

CIEE Program Managers:

W. J. Cole and C.J. Blumstein

This work was supported by the California Institute for Energy Efficiency and the Assistant Secretary for Energy Efficiency and Renewable Energy, Office of Building Technology, State and Community Programs of the U.S. Department of Energy under Contract No. DEAC03-76SF00098. CIEE is a research unit of the University of California. Publication of research results does not imply CIEE endorsement of or agreement with these findings, nor that of any CIEE sponsor. 


\title{
Table of Contents
}

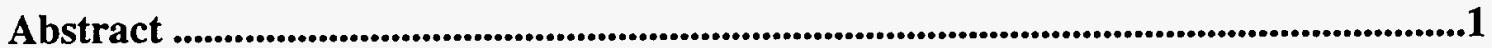

\section{Overview Report}

1. INTRODUCTION
\end{abstract}

2. APPROACH

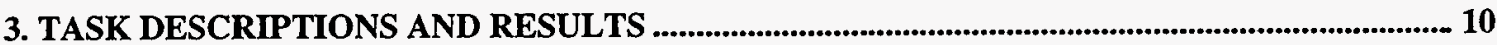

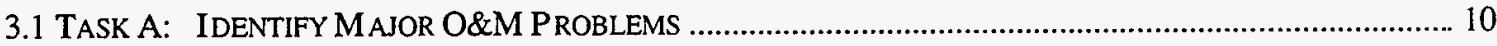

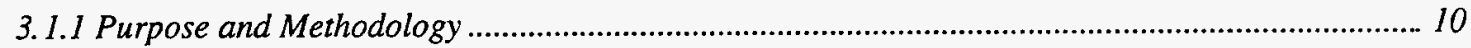

3. 1.2 Results on Identifying O\&M Problems ..................................................................................... II

3.2 TASK B: ASSESS STATE OF DIAGNOSTIC TECHNOLOGY ........................................................................ 14

3.2.I Purpose and Methodology of Assessment of Diagnostic Technology.......................................... 14

3.2.2 Results of Assessment of Diagnostic Technology ......................................................................... 14

3.3 T ASK C: SURVEY STATUS OF CURRENT AND BEST-PRACTICE SENSORS ............................................ 18

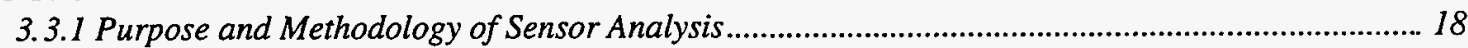

3.3.2 Results of Sensor Analysis........................................................................................................... 19

3.4 TASK D: DEFINE ECONOMIC BOUNDARY CONDITIONS ...................................................................... 22

3.4.I Purpose and Methodology of Defining Economic Boundaries.................................................... 22

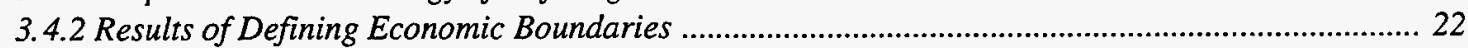

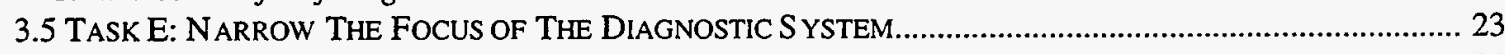

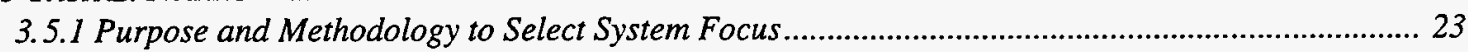

3.5.2 Results of Selecting the System Focus ...................................................................................... 24

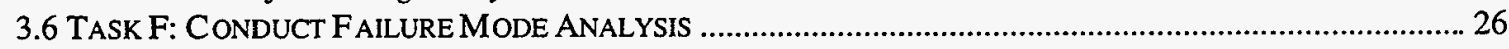

3.6.1 Purpose and Methodology of Failure Mode Analysis ................................................................... 26

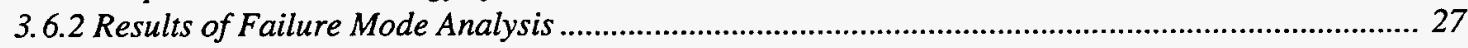

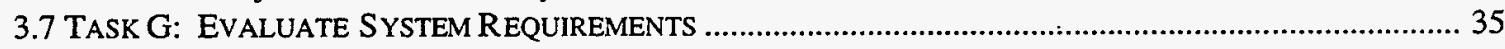

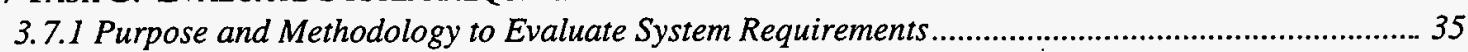

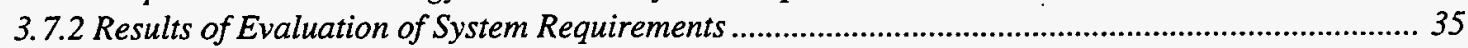

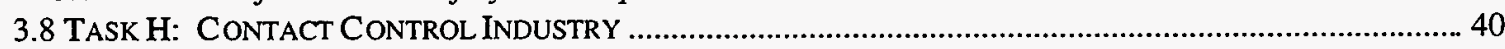

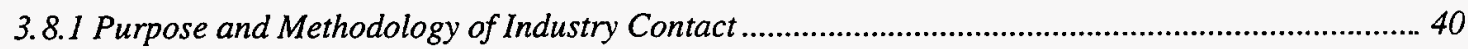

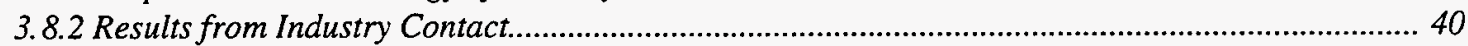

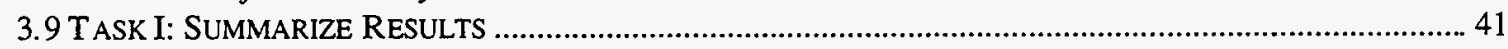

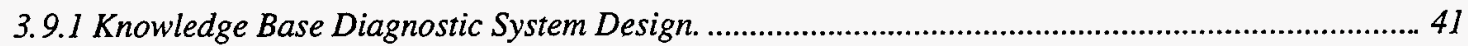

3.9.2 Summary of Objectives and Approach .............................................................................. 42

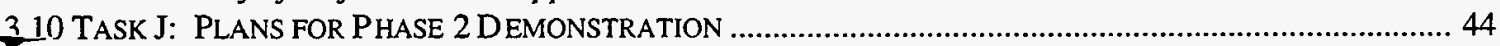

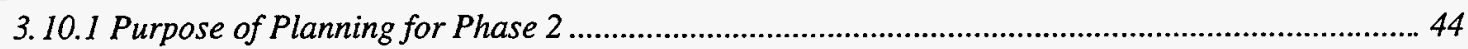

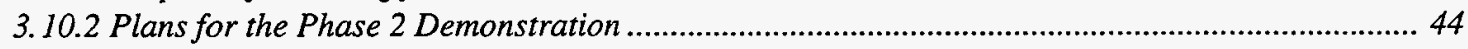

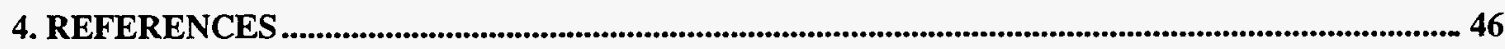




\section{LIST OF APPENDICES}

There is an extensive set of appendices that contain additional material on the Phase 1 activities. Please contact the report authors to obtain copies.

Appendix Title

Number

\begin{tabular}{|c|c|}
\hline $\begin{array}{l}\mathbf{A} \\
\mathbf{A 1} \\
\mathbf{A 2} \\
\mathbf{A 3}\end{array}$ & $\begin{array}{l}\text { Identify problems } \\
\text { Report on DOE Meeting with building operators } \\
\text { Building Performance and Commissioning Literature } \\
\text { Questionnaire }\end{array}$ \\
\hline $\begin{array}{l}\mathbf{B} 1 \\
\text { B2 }\end{array}$ & $\begin{array}{l}\text { Survey Diagnostic Tools, Methods, and Failure Modes } \\
\text { Process Monitoring and Diagnostic Techniques Used in Process } \\
\text { Control } \\
\text { The Capabilities Of Current Energy Management And Control } \\
\text { Systems (EMCSs) } \\
\text { Commercial Diagnostic Services } \\
\text { - Cooling Plant Efficiency Survey } \\
\text { - Instrumented Energy Audit } \\
\text { - Indoor Air Quality Studies } \\
\text { - Tracer Gas Studies } \\
\text { - Comfort Studies } \\
\text { Commercially Available Preventive Maintenance Technologies } \\
\text { - Vibration Analysis } \\
\text { - Sonic and Ultrasonic Methods } \\
\text { - Shock Pulse Method } \\
\text { - Thermography } \\
\text { - Oil and Lubrication Testing } \\
\text { - Electrical Testing }\end{array}$ \\
\hline $\mathbf{C}$ & Survey Sensors \\
\hline $\mathbf{E}$ & Narrow Scope \\
\hline $\mathbf{F}$ & Perform Failure Mode Analysis \\
\hline $\mathbf{G}$ & Evaluate System Requirements \\
\hline$\overline{\mathbf{H}}$ & Contact Control Industry \\
\hline & $\begin{array}{l}\text { Market Transformation Opportunities for Diagnostic Systems in } \\
\text { Commercial Buildings }\end{array}$ \\
\hline $\mathbf{J}$ & Develop Phase 2 Work Plan \\
\hline
\end{tabular}




\section{List of Tables and Figures}

TABLE 1: THE STRUCTURE OF SUPPORTING APPENDICES FOR THIS REPORT. TABLE 2: INDIVIDUAL TECHNIQUES UNDERLYING DIAGNOSTICS TABLE 3: TRADEOFFS FOR CFC CHANGEOVER

TABLE 4: SYSTEMS AND SENSORS OF THE DIAGNOSTIC SYSTEM.

FIGURE 1: TASK RELATIONSHIPS IN PHASE 1

FIGURE 2. STAGES IN THE TECHNOLOGY INNOVATION-DECISION PROCESS

FIGURE 3: A DEPICTION OF THE COMPONENTS OF A DIAGNOSTIC SYSTEM

FIGURE 4: BASELINE CENTRAL PLANT SYSTEM 20

FIGURE 5: PROPOSED SYSTEM

FIGURE 6: THREE LEVELS OF THE DIAGNOSTIC SYSTEM 25

FIGURE 7: OFFICE BUILDING ENERGY USE INTENSITIES FOR COMPARISON WITH A GIVEN $\begin{array}{ll}\text { ACTUAL BUILDING. } & 27\end{array}$

FIGURE 8: THREE-DIMENSIONAL, HOURLY WHOLE-BUILDING, CARPET PLOT. 28

FIGURE 9: CONTEXT ASSOCIATED WITH DEFINING BENEFITS OF THE DIAGNOSTIC SYSTEM.

FIGURE 10: COOLING PLANT PERFORMANCE 29

FIGURE 11: CHILLER EFFICIENCY (KW/TON VS. TONS). 30

FIGURE 12: TYPICAL MANUFACTURERS PLOT OF COOLING TOWER PERFORMANCE AND MANUFACTURER'S SPECIFICATIONS

FIGURE 13: CHILLER MONITORING SCHEMATIC

FIGURE 14: MICRO-CLIMATE VS. NANO-CLIMATE MEASUREMENT SCHEMATIC FOR COOLING TOWERS

FIGURE 15: MEASUREMENT SCHEMATIC FOR COOLING TOWERS. 39 


\begin{abstract}
Large commercial, institutional and government buildings generally do not operate at economically achievable levels of energy efficiency. Performance monitoring projects across the US have documented the potential to conserve 15 to $30 \%$ of energy use through improved operation and maintenance practices. Corresponding energy and capacity reductions for large office buildings in California are estimated to be about $42 *$ $10^{12} \mathrm{Btu} /$ year (source) in existing buildings, which includes $24 \mathrm{BkWh} /$ year (site electricity) and $32 * 10^{12} \mathrm{Btu} / \mathrm{year}$ (gas) for large office buildings. Significantly greater savings are possible from additional improvements in heating, cooling, and airconditioning system design and operation, and from extending these technologies to other building types.

The objective of this CIEE multi-year project is to develop and apply state-of-the-art continuous building performance measurement and supporting information processing and data visualization technologies. These technologies will diagnose problems in the performance of building energy systems and provide owners and managers with reliable, decision-oriented information. CIEE's goal is to assist building owners and property managers in effectively reducing energy use through improving O\&M practices and implementing opportunities for cost-effective investments in improved building energy systems. The system is being developed as a collaborative effort among researchers, building owners, utilities, and private industry. It will employ state of-the-art techniques for data collection, processing, analysis, presentation and interpretation.
\end{abstract}

The project was conducted by an interdisciplinary team to assess the current state of technology, develop an appropriate information and diagnosis capability, and test it in real buildings. The research team designed a multi-level building diagnostic system, including sensors, computer-based communications, data archival/retrieval, diagnostic information processing, data visualization and other components that would meet the needs expressed by building owners and property managers. The research team developed diagnostic and information visualization algorithms at these three levels: the whole building (Level I), the overall building cooling system (Level II), and the chiller and cooling tower subsystems (Level III).

The project team recommends that a limited number of field tests of a prototype diagnostic system should be conducted to evaluate the economic feasibility and market acceptance of this new technology. Several property managers have expressed a willingness to share the costs of these field tests. The study includes a preliminary plan for an initial field test and evaluation of this technology. 


\section{Acknowledgments}

The research team for the CIEE Project on Diagnostics for Building Commissioning and Operation is grateful to the large number of contributors who assisted in Phase 1. We are particularly grateful to Mike Brambley (Pacific Northwest National Laboratory) and Steve Blanc (Pacific Gas and Electric Company) who met with the research team several times over the course of Phase 1. Valuable feedback and review was also provided by Mark Bailey and Dennis Clough (US. Department of Energy). We appreciate the continuing support from CIEE Director Jim Cole, as well as CIEE's Karl Brown and Carl Blumstein. The project also benefited from early conversations with Jeff Haberl (Texas A\&M University) and Christie Kjellman (Southern California Edison Company). 


\section{Introduction}

Buildings generally do not perform as well in practice as anticipated during the design stage. There are many reasons for this, including improper equipment selection and installation errors, the lack of rigorous commissioning and proper maintenance, and poor feedback on ongoing performance, including energy performance. These problems are prevalent in most building systems, and frequently found in dynamic systems such as heating, ventilation, cooling, and lighting controls.

This project was conceived to develop and introduce state-of-the-art information technology in buildings in order to substantially enhance building energy performance by continuously improving operation and maintenance (O\&M). The project is being conducted by an interdisciplinary team to assess the current state of technology, develop an appropriate information and diagnosis capability, and test it in real buildings.

This document summarizes the key results from the first phase of project. The scope of the Phase 1 effort included:

- Assessing common O\&M problems and the needs of Class A office building owners and property managers to address these problems.

- Evaluating state-of-the-art building performance monitoring and diagnostic information technologies, including coordination with research involved in other promising R\&D efforts.

- Assessing the capabilities of building diagnostic technologies and related information support services, including identifying current and future suppliers of these technologies and services.

- Designing an engineering prototype of a building diagnostic system that will meet the needs of building owners and property managers.

Early in the project we decided to focus on large Class A commercial office buildings. These buildings are managed by large property management companies and we think there are potential "early adopters" among these companies. The Phase 1 market assessment activities included in-depth interviews with six technical managers who had been identified as the most sophisticated in California. These interviews included a review of their perceptions of operations and maintenance problems with all major building systems, including controls. We found it difficult to identify a single system or component that was most problematic. Rather, there are systemic problems associated with the lack of feedback available from current Energy Management and Control Systems (EMCS). Today's EMCSs are designed for control, with extremely limited capabilities in sensing, archiving, data analysis, diagnostics, and data visualization.

In the first phase of the project we concluded that significant benefits could be derived by large commercial and institutional building owners and ${ }^{1}$ operators from developing and demonstrating the use of a continuous performance tracking and diagnostic system (as

\footnotetext{
${ }^{1}$ We use the terms technical manager, building engineer, and building operator somewhat interchangeably. Technical managers will often be responsible for building engineers who operate individual buildings.
} 
Final Report; CIEE Project On Diagnostics For Building Commissioning And Operation

further described below). We produced a conceptual design for a diagnostic system that would provide continual feedback on building performance and assist operators in diagnosing operational problems. The performance data and data visualization techniques developed were designed to report on common failure modes for specific building systems discussed below. The data visualization techniques were designed to be effective computer-based graphics that display the most important metrics to describe system performance. These graphics were developed from basic engineering principles for the whole building and the water side of the cooling system. The system also includes automated data collection and analysis software that prepare the data for the visualization system. Together, the data collection, analysis, and visualization systems should serve as a robust and reliable platform for an integrated and automated diagnostic system. This evolution toward automating many of the diagnoses will be the subject of some of the Phase 2 research efforts. The diagnostic system should also be useful in allocating operations and maintenance (O\&M) resources over the short run and capital investments over the long run.

The proposed diagnostic system differs from previously developed systems in several important ways. First, it is specifically targeted toward sophisticated building operators and engineers. Most related research efforts or related techniques are targeted toward a remote expert user. Second, the proposed system is designed to be permanently installed. Related approaches that are known for being easy to use are built around short-term rather than continuous monitoring systems. Third, the monitoring system is based on laboratory-quality sensors that are far more reliable than sensors found in most commercial building systems. Fourth, the proposed system continuously archives data on approximately 80 points once each minute. Most current systems do so every 15 minutes or longer. Fifth, the diagnostic system has a top-down design that logically flows from the general whole-building analysis to system and component diagnostics. This is in contrast to bottom-up approaches that attempt to detect performance failures associated with specific individual devices.

These five features, (1) sophisticated building operators and engineers as users, (2) permanent installation, (3) laboratory-quality sensing, (4) short-interval data archives, and (5) top-down design, are critical to our proposed system. Much of this report is devoted to explaining how these departures from previous approaches increase the probability that the proposed system will perform well. As an initial test of the response to our ideas, we visited additional buildings and held two technical seminars with the managers to assess their reaction to the proposed diagnostic system. Approximately one dozen building managers have formed the core of our contact base; they have all expressed strong support for our approach and expressed an interest in participating in demonstration projects.

Based on the results of our work in Phase 1, we recommend the following focus for Phase 2. First, demonstrate the technical and economic feasibility of the diagnostic approach described in this report. This should be done in one Class A commercial building with initial efforts directed at analysis of whole-building performance and the performance of the water side of the cooling system. If the demonstration is successful it can be expanded to other building systems and possibly to a few additional Class $\mathrm{A}$ buildings to gain a broader perspective on the system's robustness and potential market acceptance. Second, conduct further research on human factors and automated diagnostics.

The reason to conduct further research on human factors is that we need to better understand how humans interact with the proposed system. Although the proposed system is only a prototype, we are concerned with its ease of use, plus the value of the information, and lessons learned from its use. If the system is too cumbersome for a 
building engineer or operator to navigate, the demonstration would be unsuccessful. Thus we want to understand what the operator likes and dislikes. Similarly, information presented by the diagnostic system that may not be considered useful or relevant to the operator would also suggest we failed to blend the correct level of simplicity and robustness. Phase 2 will also include an assessment of current research regarding machine-man interfaces for building operators.

A related issue we have explored is the difficult trade-offs between advancing the automation of the diagnostic systems versus designing the system for optimal humanbased diagnostics. The development of automated diagnostics can be justified by the recognition that building systems are becoming more complex over time and are difficult for the average operator to understand (Hyvarinen, and Karki, 1996). We have purposefully chosen to work with the most sophisticated operators we can find, as further described below. We will also explore how to automate some of the "expert diagnosis" the research team expects to conduct so that the system could be developed for a broader set of users. Automated diagnostics consist of methods to detect faults and may include identification of fault sources. Most diagnostic systems include a general user interface to aid the human user in getting information about the detection of a fault. Automated diagnostic systems generally include model-based (e.g., simple functions, physical, or black-box) fault detection and classifiers (knowledge or association based).

We also recommend that the California utilities conduct demonstrations of prototype systems. If these demonstrations are successful, we propose a collaboration with others (such as DOE, EPRI, and utilities) to promote wide-spread adoption of the diagnostic techniques demonstrated in Phase 2 and to conduct a series of market transformation activities. While the focus of this research has been on California buildings, most of the findings are general in nature and are applicable worldwide.

The demonstrations in Phase 2 should be oriented toward ensuring that the diagnostic system is cost-effective. Average reductions in whole-building energy savings of $15 \%$ have been demonstrated by compiling and assessing whole-building and major energy end-use data (Herzog and Lavine, 1992). Savings from 20 to $40 \%$ have been demonstrated in some cases (Claridge et al, 1994). With average whole-building energy costs (gas and electricity) of about $\$ 2 / \mathrm{ft}^{2}$-year, a $15 \%$ reduction translates to a savings of $\$ 0.30 / \mathrm{ft}^{2}$-year. This amounts to $\$ 150,000 /$ year for a 0.5 million $\mathrm{ft}^{2}$ building, which is the size building the demonstration projects are oriented toward. We anticipate that mature market costs for the diagnostic system will be under $\$ 75,000$ in hardware and software. Thus, the proposed system will be designed to be cost-effective for large buildings. It is worthwhile mentioning that by many accounts, these savings estimates are conservative.

Looking statewide, the target technical potential energy savings is a fifteen percent reduction in large office building energy use for California. Large office buildings (those greater than $50,000 \mathrm{sqft}$ ) in California consume about $24 \mathrm{BkWh} / y e a r$ (site electricity) and $32 * 10^{12} \mathrm{Btu} /$ year (gas). Fifteen percent savings in office energy use translates into $41.8 * 10^{12}$ Btu/year (source) ${ }^{2}$. There are about 11,000 large offices in California, which at about 100,000 sqft each, total $1.1 \mathrm{Bsqft}$ of office space. With average energy intensities of about $22 \mathrm{kWh} / \mathrm{sqft}$-year for electricity and $31 \mathrm{kBtu} / \mathrm{sqft}$-year for gas requiring about $\$ 240,000$ per year, a fifteen percent savings translates into about $\$ 35,000 / y e a r$ (Akbari et al, 1993 and Akbari et al, 1991).

\footnotetext{
$20.15 * 24$ BkWh elec. * 10240 source $\mathrm{Btu} / \mathrm{kWh}+0.15 * 32 \mathrm{BkWh}$ gas $=(36.9+4.8) * 10^{12}$ Btu $($ source $)=42 * 10^{12}$ Btu (source).
} 
Additional peak demand savings are likely, and not included here. Furthermore, it is likely that with the use of a diagnostic system like that described below, additional HVAC savings are possible. These additional savings are likely to be achieved from improved equipment sizing given reliable data on actual cooling loads. Some examples of this are presented. Finally, greater statewide savings are also possible from extending these technologies to other building types.

The next section of this report outlines the research approach. The third section describes each task and its key results. Each of these sections is covered in more detail in the Appendices . 


\section{Approach}

This project is divided into two phases. Phase 1 was to conduct a series of background analys es to design a diagnostic system to be tested in several actual buildings in Phase 2 . The background analysis was conducted as ten individual tasks. The task descriptions were developed in a series of project scoping meetings with the project sponsors. These are as follows:

A. Identify Problems - Identify major O\&M problems (from literature searches, interviews with building engineers and operators, existing case studies, etc.).

B. Assess State of Diagnostic Technology - Investigate and evaluate diagnostic methods, tools, and techniques methods for automating diagnosis, and examine how these methods are used to evaluate common modes of failure. ${ }^{3}$

C. Survey Sensors - Survey the status of common practice and state-of-the-art sensors

D. Define Economic Boundary Conditions - Define a set of economic boundary conditions for cost-effectiveness analysis

E. Narrow Scope - Synthesize results plus develop and apply criteria to select a set of building systems for the prototype diagnostic system. Select the building system for the focus of the diagnostic system.

F. Perform Failure Mode Analysis - Analyze major modes of failure for the selected set of candidate building systems and evaluate diagnostic techniques for detecting and diagnosing these modes.

G. Evaluate System Requirements - Evaluate requirements for sensors, data analysis, and data processing, for the selected set of candidate systems.

H. Contact Control Industry - Contact the control industry to identify related activities and explore opportunities for collaboration.

I Summarize Results - Summarize findings and describe the system to be deployed.

J. Develop Phase 2 Work Plan - Prepare a work plan for the Phase 2 field test.

The field of building diagnostics is extremely broad. The project began with a broad charter and it became clear early in the project's development that we would identify a limited set of building systems for the project's focus. Part of the Phase 1 analysis was oriented toward identifying the most feasible system or systems. The rationale for choosing the whole-building and cooling system chillers and cooling towers is presented below.

CIEE asked the project team to focus on large Class A office buildings. Class A office buildings represent the most prestigious buildings in the office market ${ }^{4}$. They have above average rents, high quality standard finishes, state-of-the-art building systems, exceptional accessibility, and a strong market presence. Class A building owners and operators are among the most sophisticated in the commercial sector. They are considered innovative, and early adopters of emerging technologies. Several building

3 This activity was considered as two separate tasks in the original task description: 1) Investigate and evaluate diagnostic approaches, and 2) Survey failure mode analysis techniques.

4 The Building Owners and Managers Association classifies office buildings as follows:

Class A buildings: The most prestigious buildings in the particular market that have above average rents, high quality standard finishes, state of the art systems, exceptional accessibility, and a definite market presence.

Class $B$ buildings: Buildings in a particular market that compete for a wide range of tenants with rents in the average range for the market. Building finishes are fair to good and systems are adequate, but the buildings cannot compete with Class $A$ at the same rent level.

Class C buildings: Buildings seeking tenants requiring functional spaces at rents below the average for the market area. 
owners and operators have expressed a strong interest in collaborating with the research team on a field demonstration of the prototype diagnostics system. One benefit of performing the field test demonstrations with Class A building operators is that the property management companies who operate the buildings tend to have large real-estate portfolios. They indicate that they are eager to utilize lessons learned during the demonstrations in their other buildings, thus the approaches we explore could propagate rapidly throughout similar buildings. Additional factors regarding the selection and advantages of collaborating with this market segment are described below. Although the tasks are listed in alphabetical order, they are not sequential.

Figure 1 shows how the tasks are related. Tasks A through D formed the basis for selecting the individual systems in Task $\mathrm{F}$ as the focus of the diagnostic system. This was followed by initial contacts with manufacturers (Task $\mathrm{H}$ ). The failure mode analyses (Task F) were conducted for the selected building energy systems. The technical requirements of the diagnostic system (Task $G$ ) were developed as an integral component of Task F. The results of Tasks F and $G$ formed the basis of the prototype development plan described in Task I. The next section (Section 4) presents a summary of the methodology and key findings for each task. In cases where the tasks are closely related we discuss the methodology and findings for a group of tasks.

\section{Figure 1: Task relationships in Phase 1}

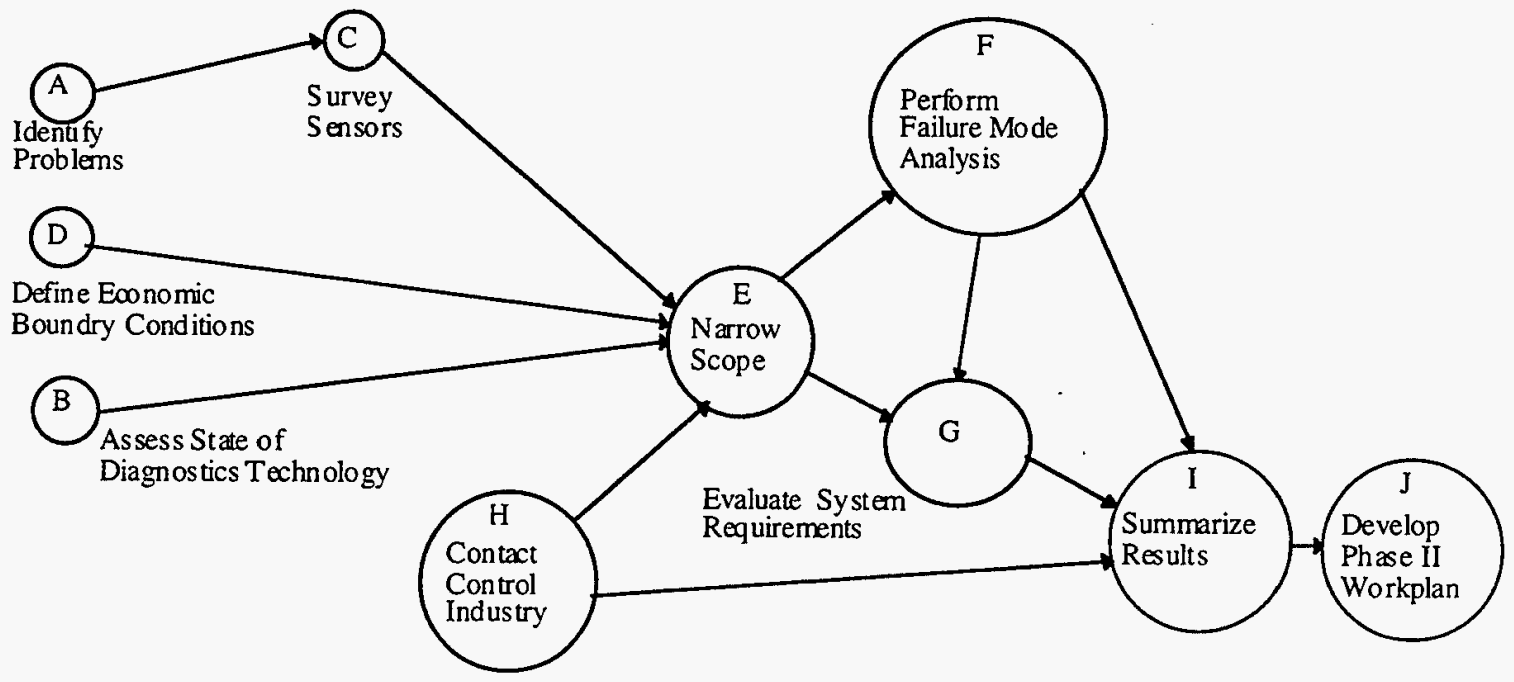


Table 1: The structure of supporting appendices for this report. There are two levels. Those designated with a single letter (e.g. A) are the main reports on a given task. Those with a letter followed by a number (e.g. A2) are ancillary reports on topics underlying the topic specified by the letter.

\begin{tabular}{|c|c|}
\hline Appendix Number & Title \\
\hline A & Identify Problems \\
\hline A1 & Report on DOE Meeting with Building Operators \\
\hline A2 & Building Performance and Commissioning Literature \\
\hline A3 & Questionnaire \\
\hline $\mathbf{B}$ & Survey Diagnostic Tools, Methods, and Failure Modes \\
\hline B1 & $\begin{array}{l}\text { Process Monitoring and Diagnostic Techniques Used in } \\
\text { Process Control }\end{array}$ \\
\hline B2 & $\begin{array}{l}\text { The Capabilities Of Current Energy Management And } \\
\text { Control Systems (EMCSs) }\end{array}$ \\
\hline B33 & $\begin{array}{l}\text { Commercial Diagnostic Services } \\
\text { - } \quad \text { Cooling Plant Efficiency Survey } \\
\text { - } \quad \text { Instrumented Energy Audit } \\
\text { - } \quad \text { Indoor Air Quality Studies } \\
\text { - } \quad \text { Tracer Gas Studies } \\
\text { - Comfort Studies }\end{array}$ \\
\hline B4 & $\begin{array}{l}\text { Commercially Available Preventive Maintenance } \\
\text { Technologies } \\
\text { - Vibration Analysis } \\
\text { - Sonic and Ultrasonic Methods } \\
\text { - Shock Pulse Method } \\
\text { - Thermography } \\
\text { - Oil and Lubrication Testing } \\
\text { - Electrical Testing }\end{array}$ \\
\hline $\mathbf{C}$ & Survey Sensors \\
\hline $\mathbf{E}$ & Narrow Scope \\
\hline $\mathbf{F}$ & Perform Failure Mode Analysis \\
\hline $\mathbf{G}$ & Evaluate System Requirements \\
\hline “ت̈ & Contact Control Industry \\
\hline I' & $\begin{array}{l}\text { Market Transformation Opportunities for Diagnostic Systems } \\
\text { in Commercial Buildings }\end{array}$ \\
\hline $\mathrm{J}$ & Develop Phase 2 Work Plan \\
\hline
\end{tabular}




\section{Task Descriptions and Results}

\subsection{Task A: Identify Major O\&M Problems}

\subsubsection{Purpose and Methodology}

The purpose of this task was to identify major O\&M problems in commercial buildings. This was a broad exploratory task to identify opportunities for automated diagnostic systems. As mentioned, this task was done prior to narrowing the focus of the diagnostic system. We assumed a broad definition of the concept of an O\&M problem: an O\&M issue that caused an increase in energy use beyond the expected performance of a building system. For example, a cooling tower that operates when the chillers are off causes unnecessary energy use. The expected performance is for the tower schedule to be coordinated with the chiller schedule, but such problems are common in commercial buildings.

Our initial plan was to develop a list of the major classes of O\&M problems along with their severity and frequency. This plan had to be modified due to the broad nature of O\&M problems found in commercial buildings, as further discussed below. The two primary sources of information use in this task were: (1) review of published literature and analysis of existing case study data, and (2) interviews with building engineers and operators, and industry O\&M workshops. The review of published literature included evaluating conference proceedings and journal articles discussing the relationship between O\&M and energy use in commercial buildings. The research team also drew upon their own experience and research efforts to evaluate O\&M problems. Research results from demonstration projects and programs such as Texas A\&M University's LoanSTAR program (Haberl et al, 1996), PG\&E's Advanced Customer Technology Test (Hernandez and Brohard, 1994), Bonneville Power Administration's Energy Edge Program (Piette et al, 1994), and Pacificorp's Energy FinAnswer Commissioning program (Piette et al., 1995, Yoder and Kaplan, 1992) were considered.

The second source of information we drew upon was the results of detailed, personal indepth interviews and feedback from building owners and operators. These interviews were based on an extensive, 50-page, questionnaire ${ }^{5}$ designed to tabulate O\&M problems and characterize building owners' and operators' experiences with diagnostic and control technologies. The questionnaire contained detailed sections asking about commissioning practices, organization of maintenance activities, the use of preventative maintenance diagnostic technologies ${ }^{6}$ (e.g., vibration analysis, thermography, etc.), Energy Management and Control Systems (EMCS) ${ }^{7}$, sensor maintenance and calibration. The research team toured fifteen facilities to obtain first-hand experience with current control technologies and the way operators interact with them.

Another important element in the methodology of Task 1 was the analysis and application of technology innovation and adoption theory (Figure 2) ${ }^{8}$. We selected a series of Class A building operators because of their role in the commercial building market as "early adopters" of advanced technologies. We purposefully worked with the

5 See Appendix A3.

6 See Appendices B3 and B4.

7 An entire Appendix (Appendix B2) is dedicated to explication of the capabilities of current EMC systems.

8 See a detailed discussion in Appendix I. 
Building Owners and Managers Association to identify the most sophisticated and innovative building engineers and operators in California.

The analysis is based on the classic work by Rogers (1983) who suggested that technology adoption can be described by five categories: innovators, early market, early majority, late majority, and laggards. As an example of how the categories differ, "innovators" pursue technology and sometimes make a purchase simply for the pleasure of exploring a new idea or device, while "early adopters" are interested in new technology for its own sake and are quick to understand and appreciate the benefits of new products. This is why early adopter have been selected for this project.

The companies selected for the O\&M surveys had the characteristics that Rogers deemed important. First, they had some organizational "slack" to pursue new ideas and had developed a method to analyze innovations utilizing this slack time. Second, they had made someone in their organization responsible for the technology strategy. Although they do not have formal R\&D departments, they have identified a role of technology evaluator. Finally, they had demonstrated by past performance that they could think creatively and would act on new information in previous innovations we evaluated. The interviews with building operators also included discussions with the building managers about the diagnostic technology (described in Task B) to understand the deliberate steps of the process used to make a technology adoption or rejection decision (Figure 2).

Figure 2: Stages in the Technology Innovation-Decision Process (Rogers, 1983).

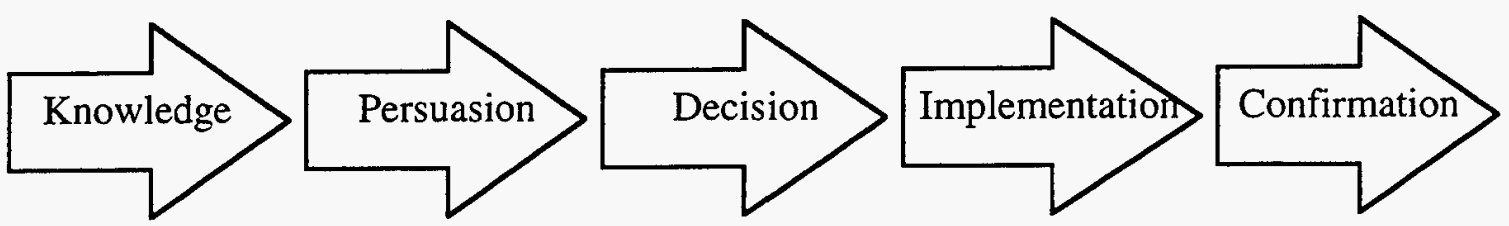

\subsubsection{Results on Identifying O\&M Problems}

Before discussing the results of the on-site interviews it is useful to summarize key findings from related literature. First, it is important to recognize that virtually all buildings have some sort of O\&M problems. Second, most buildings are not carefully commissioned. Previously published case studies indicated that careful review of hourly end-use and whole-building energy performance data can result in savings equivalent to about 15 percent of annual operating costs (Herzog and Lavine, 1992, and Claridge et al, 1994). These savings are much greater (up to 40 percent) in some cases.

Previous commissioning case studies have included lists of common O\&M problems 9 (Piette et al, 1996). For example, a set of miscellaneous problems might comprise the following issues:

- Condenser water variable frequency drive not enabled

- Economizer damper stuck closed

- Chiller cycling too frequently

- Cooling tower fan cycling too frequently

- Variable-air-volume box stuck in cooling mode

- Reheat fans not enabled

- Malfunctioning pressure sensor

9 See Appendix A2 
The difficulty with identifying all common O\&M problems is that reports of these problems tend to be anecdotal rather than statistically significant. Instead of identifying a detailed set problems, we found a more critical and diverse set of structural problems ${ }^{10}$ that need to be addressed by any successful diagnostic approach.

The on-site interviews were based on an O\&M questionnaire designed by the project team to structure information collected from building personnel. The idea was to identify their most important problems in O\&M, after which we would tabulate and focus on the most common ones. Instead of generating these kinds of seemingly straightforward results, the underlying problem turned out to be much more complex. We expected, but did not generate a list of common specific problems for which we could generate a clean set of diagnostics.

Next, we summarize the key problems we identified and then give a brief description of five important constraints that must be taken into account in designing a useful system.

\subsubsection{Key Problem: Lack of Good Information on Major Building Systems.}

The key problem we identified is that the information tools currently in use in these buildings severely limits a building manager's ability to assess their own O\&M practices in a comprehensive manner. As mentioned, the questionnaire had sections asking about continuous information systems such as EMCSs, as well as one-time and short-term diagnostics such as vibration analysis and thermography. The most significant conclusion from the surveys and literature search is that building managers have little information on the energy performance of their major building systems, such as the cooling plant, lighting, and ventilation. They therefore have very limited capabilities to:

- detect and diagnose problems or

- evaluate the economic benefit of modifying O\&M practices or changing existing equipment with more efficient equipment.

The general problem of lack of information on major building systems comprises a series of specific problems. For example, the most sophisticated building managers reported problems in keeping sensors properly calibrated. Thus, the information directly available from the EMCS is questionable. Temperature, humidity, and flow sensors were all reported as problematic, with the most concern over humidity and flow sensors.

\subsubsection{Five Important Constraints}

The following five constraints were also found to be significant in evaluating opportunities for a continuous diagnostic system.

\section{Constraint 1: Black Box Technical Complexity Confuses Operations.}

Class A building engineers want to understand how their control and diagnostic systems operate. For a variety of reasons, current advanced control systems often fail in this regard. Many control systems use proprietary, black-box control algorithms, making it difficult for operators to understand and assess the impact of changes in control strategies. There is a significant challenge to the buildings industry to integrate operators and sophisticated systems in order to provide optimal results. Clear feedback to an operator on how the technology functions is essential but frequently nonexistent in current systems.

10 Frequently these are associated with current methods of building management. 


\section{Constraint 2: Economic Constraints Limit Innovation.}

Building managers operate in a tight economic environment. Investments in building systems must have defensible estimates of energy and cost savings. These investments must ultimately lower tenant costs and have a quick payback. New or retrofitted systems that do not produce expected savings can seriously jeopardize one's career. Diagnostic systems must provide defensible cost-benefit information in a usable form if investments in improved O\&M or retrofits are to be approved.

Constraint 3: Energy Cost Reduction is not a Top Priority.

Building managers compare the annual energy use and costs of individual buildings with others for which they have data. These data may be from their own portfolio, from trade association statistics, or from utility data. Most building managers do not seek aggressive reductions in annual energy use and associated energy costs provided that their building is not dramatically far from other benchmark data. Rather, building managers and engineers spend significant time responding to complaints and seeking to maintain high standards of comfort and indoor air quality. Similarly, preventative maintenance is of great interest. A diagnostic system that assists in these areas as part of the effort to reduce energy costs is desirable.

Constraint 4: Lack of Knowledge of Information Technology Limits Innovation. Building managers are interested in strategies to improve the energy performance of their buildings, but lack the training in new information tools needed to conceptualize and evaluate the next level of building efficiency technologies. The computer facilities available to them are limited.

\section{Constraint 5: Poor Initial Designs Cause Ongoing Problems.}

The most common problem reported by the managers was that critical equipment was often poorly (either under or over) sized. The second most common problem reported was that some aspect of the equipment layout was faulty. These managers see these problems as continual issues in achieving optimal operations. They currently have no formal mechanism to document these problems, economically justify retrofits or provide feedback to designers, which might help ensure that the problems are not repeated in the future.

\subsubsection{Findings on Technology Innovation}

After identifying the innovative operators we sought to identify the process of innovation utilized in the past by evaluating the process used to adopt related characteristic innovations. These "scouting" studies resulted in an understanding of the business and technical constraints and incentives for innovations. Specifically, we found that the technical managers responsible for innovation frequently conducted pilot studies with their own operating budgets. Furthermore, we found that the technical managers responsible for innovations were limited to evaluating simple components and were unable to undertake large scale studies of potential "system-wide" technologies because they could not justify the cost and time for such studies.

We found that the technical managers were unconsciously using the process described by Rogers. They usually were made aware of new technologies be a vendor salesman. Another way to learn about new technologies is to hire an employee of a company that had already tried it. We learned that these managers did not have much (almost no) interaction with mechanical or electrical design engineers. 


\subsection{Task B: Assess State of Diagnostic Technology}

\subsubsection{Purpose and Methodology of Assessment of Diagnostic Technology}

The purpose of Task B was to investigate and evaluate diagnostic methods, tools, and techniques for inclusion in the current project. We conducted a broad review of possible approaches for diagnostics and determined the degree of technical maturity with which each has been applied to building problems. As described in detail in the next section, we defined a set of criteria and then evaluated options in terms of these criteria. The analysis considered issues such as required sensor and communications technology, bottom-up versus top-down diagnostics architecture, and the design of temporary versus permanent systems. We also examined the status of techniques from the field of intelligent systems (e.g., artificial intelligence, fuzzy logic, neural networks) and diagnostics used in process control industries. Results are summarized here with more details in Appendices B, Bl, $\mathrm{B} 2, \mathrm{~B} 3$ and $\mathrm{B} 4$.

\subsubsection{Results of Assessment of Diagnostic Technology}

The appendices supporting the analysis methods and results from this task comprise a main appendix and four sub-appendices:

Appendix B. State of Diagnostic Systems and Related Technology - This detailed discussion reviews the basic elements of a diagnostic system, the criteria used to evaluate the technologies, a discussion of EMCS, sensors and communications technology, an overview of bottom-up and top-down diagnostic systems. It also includes a discussion automated versus hands-on, manual fault-detection methods.

Appendix B.1. Process Monitoring and Diagnostics Techniques Used in Process Control - This appendix summarizes the state of diagnostic technology in process control to evaluate what approaches may be viable in buildings.

Appendix B.2. The Capabilities of Current EMCSs - This appendix reviews EMCS functions diagnostic systems, sensors and transducers.

Appendix B.3. Commercial Diagnostic Services - This appendix provides a broad overview of commercial diagnostic services.

- Cooling Plant Efficiency Survey

- Instrumented Energy Audit

- Indoor Air Quality Studies

- Tracer Gas Studies

- Comfort Studies

Appendix B.4. Commercial Preventative Maintenance Services - This appendix provides a broad overview of commercial preventative maintenance services. 
- Vibration Analysis

- Sonic and Ultrasonic Methods

- Shock Pulse Method

- Thermography

- Oil and Lubrication Testing

- Electrical Testing

Here, we are concerned with assessing the availability of technologies for application to an advanced diagnostic system. We want to know what will be needed, and how much development will be required. A diagnostic system comprises the components depicted in Figure 3.

Figure 3: A depiction of the components of a diagnostic system

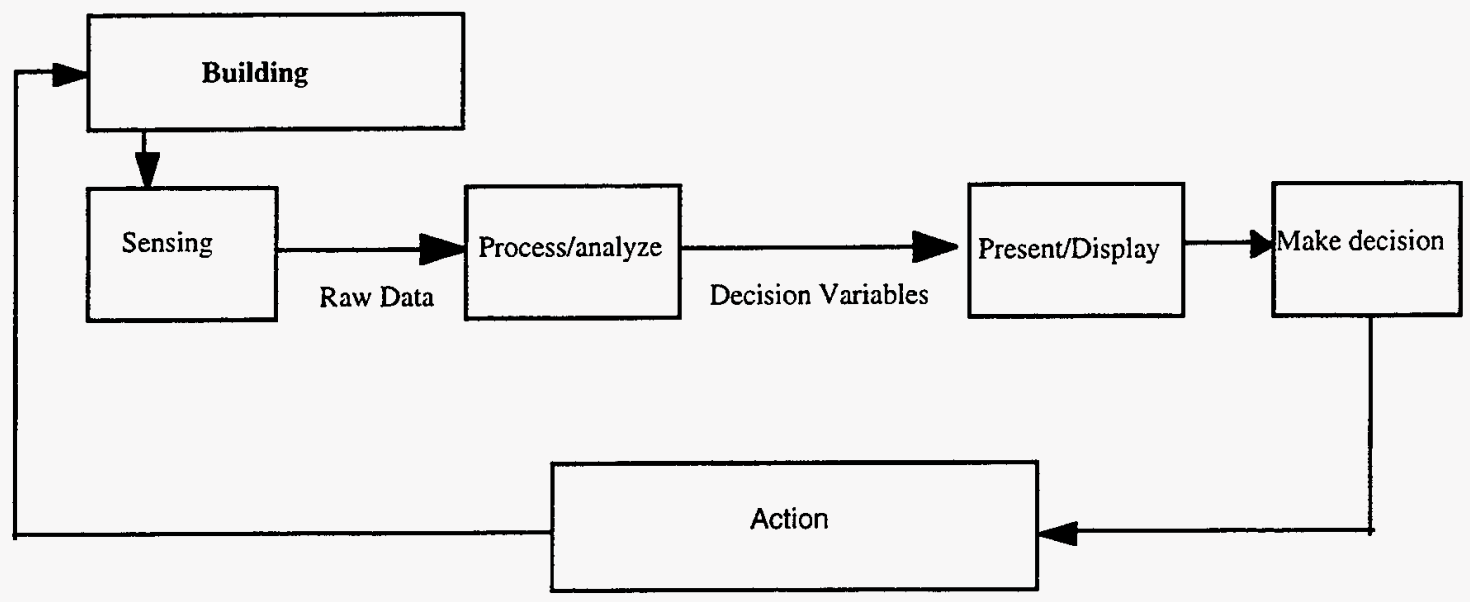

There are many approaches for each of the components, so one must define a set of criteria and evaluate the suitability of the approaches. We used the following six criteria:

- Diagnoses must be understandable to building technical personnel. In other words, the resulting system must make diagnoses using a process that building engineers understand (perhaps after some training).

- Resulting diagnoses generated by the system must be believable to building engineers. In order to act on the diagnoses, building engineers must make recommendations to upper management under tight financial constraints. Given the career risks involved, this process will only be undertaken if the diagnostic system presents credible evidence of its findings.

- Diagnostic approaches must be robust in the sense that they can be gainfully applied to a specific building without an enormous amount of tuning. This can either be the result of extensive work by others certifying that a technique works on a large group of building applications (including the specific test building) or it could be the result of some inherent property of the technique that grants it very broad and easily defended applicability to a large group of buildings (including the specific test building. 
- Diagnostic components for individual building components must coexist, cooperate and integrate in order to a) be able to work together on separate systems within a building and $b$ ) to permit expansion of the system to other building components.

- Diagnostic approaches must be easy to implement at reasonable cost. - The design of the initial diagnostic system must lead naturally to increased
automation in later phases.

Furthermore, one needs to focus on different levels of detail in terms of high level issues like system architecture and lower level issues such as algorithms. Finally, the boxes in Figure 3 are interdependent. For example, a very limited information base (e.g. due to poor sensing or infrequent archival) will typically greatly increase the amount of processing and will need to be based on assumptions about error models and models for building components. We need to keep in mind such constraints in evaluating the options. The overall architecture of diagnostic systems includes:

- bottom-up and top-down approaches

- human fault detector, automatic fault detector, or hybrid methods

- temporary, short-term systems or permanently installed systems

In Table 2 of Appendix B, we summarize the application of the criteria to the following options:

Architecture

- Top down

- Bottom up
Fault detection

- Automatic 11

- Human ${ }^{12}$

\section{Examples of technical approaches}

- Neural networks

- Artificial intelligence

- Fuzzy logic

- Techniques from process control

- Data visualization techniques

We concluded that for the target Class A office buildings, the top-down architecture is more promising. This is because it is more robust, integrates better, costs less to design, and is easier to automate. Similarly, human assistance in fault detection appears more promising in the near term ${ }^{13}$. Increased automation is a viable longer term strategy as data collection is improved and automated techniques will be easier to build. Automated techniques require training statistical models with data sets that are limited by current building monitoring systems. After building the models one must test their ability to detect various categories of faults.

The first prototype system should concentrate on creating a robust monitoring and database infrastructure using credible sensing, data visualization and top-down architecture, while postponing the development of automation until future phases of the

11 Here, the question of whether the human understands and believes the automatic diagnosis is paramount.

12 Here, the key is that if operators make the diagnoses in concert with the computer, they must be trained to understand what the computer displays mean. This makes for much increased levels of understanding, confidence etc.

13 The concept here is to combine the team expertise with the knowledge that sophisticated building engineers and operators have about their own building, providing them with tools to make decisions about improvements in operations. Such an approach may not be the most valuable method for other buildings where the operator is less sophisticated, but our analysis of building operators in Class A buildings shows that they strongly desire the system capabilities we've outlined. 
project. This does not imply that automation is unimportant, or should not be aggressively pursued. It simply implies that the order in which things are done be carefully reasoned. We summarize the state of applicability of the various technological approaches as follows (Table 2). The approach that we currently plan to implement combines several of the methods listed.

Table 2: Individual Techniques Underlying Diagnostics

\begin{tabular}{|l|ll|}
\hline Method & Industrial & Building \\
& Applications & Applications \\
1. Signal conditioning of raw measurements & Widespread & Widespread \\
2. Engineering calculations based on sensor data & Widespread & Widespread \\
3. Statistical monitoring techniques & Widespread & Limited \\
4. Model-based residual analysis & Limited & Limited \\
5. Knowledge-based expert systems & Limited & Limited \\
6. Neural networks and pattern recognition & Limited & Limited \\
7. Fuzzy logic & Limited & Limited \\
\hline
\end{tabular}

We found that there are many relevant approaches to diagnostics that have been used to varying degrees in problems like the one at hand. One must distinguish between the level of theoretical development of the method itself and the degree to which reliable working systems are available or can be built to implement the diagnoses needed in this project. Some of these techniques (e.g. neural nets) typically require significant effort to design and test on a specific problem. The proposed diagnostic will provide extensive data for their development should they become attractive in Phase 2.

\section{Differences between the Proposed System and Previous Related Approaches}

While many of the tools can be interchanged, the proposed system differs in application from similar work at Texas A\&M (Haberl et al, 1996; The Energy Systems Lab (ESL) Home Page, 1996), which is specifically oriented toward building researchers and others interested in tracking the performance of multiple buildings enrolled in energy efficiency programs. Our approach differs from those developed at ESL in that the system being proposed here is oriented toward having the building technical staff as the primary user. Our approach is similar in that we're developing an integrated information system that includes monitoring systems, data management systems, communications data visualization, and remote access.

However, there is room for eventual synergy and interaction. For example, although the proposed system differs substantially from that used at ESL, The Energy System's Lab at Texas A\&M has developed a package of powerful monitoring systems and software analysis tools that allow one to perform ongoing analysis of energy savings from retrofits and identify O\&M improvements. These systems are available to building researchers and others interested in tracking the performance of multiple buildings. Integration could take many forms, but substantial differences exist in sensing, archiving, visualization and computing platform between that used at ESL and that proposed here.

Our work clearly builds on previous work by Lee Eng Lock (of Supersymmetry, see for example Lee and Hibberd, 1992). However, the proposed system would extend his primary efforts in several ways. First, we're testing the first automated information system with more detailed metering than has been previously tested in large commercial buildings. Much of Mr. Lee's previous work emphasized monitoring of clean rooms. We are using the findings from these process control applications, and applying them to large office buildings. Another advance from his previous work is the effort to simplify the user interface and create standardized graphics. This packaging is a critical component of the proposed system, allowing the system to be used by a building operator 
who has minimal knowledge of computers. Third, we are developing a framework for the data and information organized into a knowledge base, further described in later sections of this report. Like the ESL and SuperSymmetry systems, the proposed system is designed to be permanently installed. Some related approaches, such as those described by Waterbury et al. (1992), are known for being easy to use but are built around short-term rather than continuous monitoring systems.

\section{Current EMCSs}

The O\&M surveys in Task A revealed that commercial building operators are skeptical about current EMCS monitoring. We have carefully examined monitoring systems used with building metering projects and current EMCSs. The proposed system is based on laboratory-quality instrumentation to ensure that the data are more reliable, believable, and robust than those found in today's state-of-the-art EMCSs and related monitoring systems, which are discussed in more detail later in this report. Not only are the instruments of higher-quality than in typical related systems, but the proposed system also has a higher-resolution time scale, continuously archiving data on approximately 80 points for a single building once each minute. Most current systems do so every 15 minutes or longer.

Another unique facet of the diagnostic system is the top-down design that logically flows from general whole-building analysis to system and component diagnostics. This approach stands in sharp contrast with bottom-up approaches that attempt to detect performance failures associated with specific individual devices assuming a fixed range of operating conditions (in the face of the great diversity of conditions found in realworld applications) (Hyvarinen and Kohonen, 1993). A top-down system design is particularly useful in our project in which we utilize the knowledge of sophisticated onsite operators.

\subsection{Task C: Survey Status of Current and Best-Practice Sensors}

\subsubsection{Purpose and Methodology of Sensor Analysis}

The five questions this task evaluated are:

- How good does sensor accuracy need to be for robust measurement and diagnostics?

- Are current sensors commonly used in buildings adequate for these diagnostics?

- Can one purchase adequate sensors in cases where commonly used sensors are not adequate?

- Can one economically justify the use of the latter sensors in real buildings?

- Is sensor calibration a problem in commercial buildings?

These questions were examined by identifying the physical quantities that must be sensed in commercial buildings (e.g. temperatures, pressures, and flows), and evaluating current sensor technologies in each case. This task is not about sensor implications associated with use of techniques such as analysis of electrical harmonics or acoustic signatures. Instead it is about basic issues of sensor cost, availability, durability of accuracy and required levels of accuracy. 


\subsubsection{Results of Sensor Analysis ${ }^{14}$}

\section{How good does sensing have to be?}

There are two important things the proposed system will need to accomplish: correct diagnoses of building problems, and credible cost-benefit information on potential corrections for diagnosed problems ${ }^{15}$. Sensors are crucial in both respects. There is a crucial tradeoff between sensor accuracy and archival frequency, and a system's ability to make correct diagnoses. Up to some limit, one can compensate for lack of sensors or even accuracy of sensing by use of more complex processing. Therefore, one can spend less money on sensing and more money on algorithm development and perhaps computer power. Such processing inevitably involves assumptions such as key building parameters and sensor error characteristics. Incorrect assumptions lead to incorrect diagnoses. A similar tradeoff exists in terms of the cost-benefit analyses. Again, poor sensing necessitates additional assumptions and again, those assumptions may be wrong.

High quality, reliable data are needed to correctly control building systems and incorrect measurement can result in energy increases. For example, a $2^{\circ} \mathrm{C}$ error in dew point sensing can cause a $30 \%$ increase in pumping energy for a strategy where air-handlers are controlled to maintain a constant dew point. The control region is an area where the hyperbolic relationship between coil dew point and chilled water flow is steep. Reducing pump energy by the use of a more accurate sensor easily pays for the higher-precision sensor. Reliable sensing is especially important for differential temperature and liquid flow measurements. Important data such as chiller load depend on accurate flow measurements. This is especially important in diagnosing chiller problems, properly sizing chillers and in analyses of retrofits.

Correct sequencing of chillers is also directly related to sensor accuracy. A large commercial control system turns on a second chiller when the load gets to $90 \%$ of the first chiller's rated capacity. If the load is only slightly larger than the capacity of a single chiller, both chillers will be running at far less than their optimal efficiency. Sensor quality is important here. If one has inaccurate information on actual delivered tons, the actual load may not be as high as sensed, and the second chiller is not really needed. If the load is only slightly higher than the capacity of the single chiller, one may be able to compensate by running more cooling towers. In either case, better sensing yields higher chiller efficiencies.

As another example, sensing accuracy can have a profound effect on resizing and CFC phase outs. As seen in an example in Section C.6.4.4 of Appendix C, let us imagine an existing plant as depicted in Figure 4 . This plant has a 500 ton chiller running CFC-R-11 and operating at $0.75 \mathrm{~kW} /$ ton with $110 \mathrm{~kW}$ of fan and pumping power distributed among the chiller and cooling tower loops. Assume the chiller is oversized and the actual load is only 400 tons. Such a chiller would generate a temperature differential $(\Delta \mathrm{T})$ ranging from about $10^{\circ} \mathrm{F}$ at $100 \%$ load to about $0.7^{\circ} \mathrm{F}$ at no load. If a CFC change is needed, several alternatives exist: For example, the choice for a new chiller might consist of changing from R-11 to R-123 and absorb the efficiency penalty (approximately $8 \%$, as shown in scenario 1 in Table 3 ). Another scenario is that with more accurate cooling load data, one could install a new, smaller chiller with better efficiency (e.g.400 ton@ $0.60 \mathrm{~kW} /$ ton, see Figure 5, and scenario 2 in Table 3).

14 This analysis is described in Appendix C.

15 As mentioned in the results of Task A above, accurate cost-benefit analyses are crucial. The building engineers need a mechanism to prioritize their efforts. Cost-benefit analysis errors lead to incorrect priorities. Furthermore, financial managers demand credible cost-benefit calculations before committing resources to a retrofit. 
Table 3: Tradeoffs for CFC Changeover

\begin{tabular}{|l|l|l|l|}
\hline & $\begin{array}{l}\text { Baseline: } \\
\text { Present Chiller }\end{array}$ & $\begin{array}{l}\text { Scenario 1: } \\
\text { Change to R-123 } \\
\text { alone }\end{array}$ & $\begin{array}{l}\text { Scenario 2: } \\
\text { Downsized } \\
\text { Chiller }\end{array}$ \\
\hline Chiller kW & $500^{*} 0.75=375$ & $500 * 0.81=405$ & $400^{*} 0.6=240$ \\
\hline Pumping/fans kW & 110 & 110 & 56 \\
\hline $\begin{array}{l}\text { Annual cost @ } \$ 770 \\
\text { for 1 kW per year }\end{array}$ & $\$ 373,450$ & $\$ 396,550$ & $\$ 228,166$ \\
\hline $\begin{array}{l}\text { Annual savings from } \\
\text { baseline }\end{array}$ & & $\begin{array}{l}\$ 23,100 \\
(8 \% \text { increase) }\end{array}$ & $\begin{array}{l}\$ 145,284 \\
\text { (38\% savings) }\end{array}$ \\
\hline
\end{tabular}

Note that the new chiller price has not been included here. There are two scenarios. First, if one changes to R-123, the entire price of the chiller needs to be offset by the additional savings. Alternatively, if one needs to change the chiller anyway (e.g. because of a change to R-134A) then one actually saves money since the smaller chiller costs less than the larger one that would have been installed. With limited data on actual loads, owners normally purchase identical sized chillers. With reliable measurements you can often downsize, reducing both capital and operating costs. The result is a difference of $0.81 \mathrm{~kW} /$ ton against $0.6 \mathrm{~kW} / \mathrm{ton}$, or $20 \%$ savings.

Pumping energy is also reduced with a smaller chiller sized more closely to the measured peak load. Assume that a 425 ton chiller is installed to allow for some minor load growth. The pumping for the new chiller would be $(425 / 500)^{3} \times 110 \mathrm{~kW}=0.614 \times 110=$ $67.5 \mathrm{~kW}^{16}$. At an annual cost of $\$ 770$ for one $\mathrm{kW}$ at 8760 hours of operation ${ }^{17}$ one would save $(110-67.5) \times 770=\$ 32,725 / \mathrm{yr}$.

Figure 4: Baseline Central Plant System

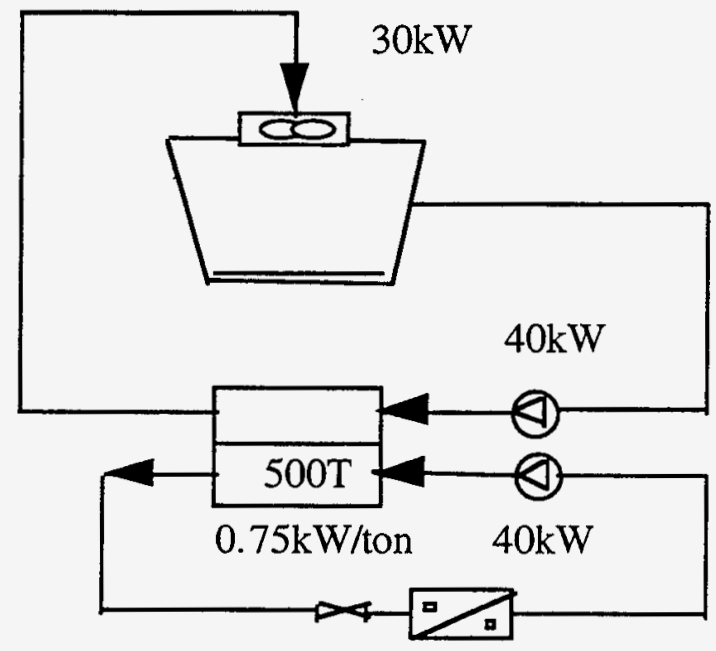

Figure 5: Proposed System

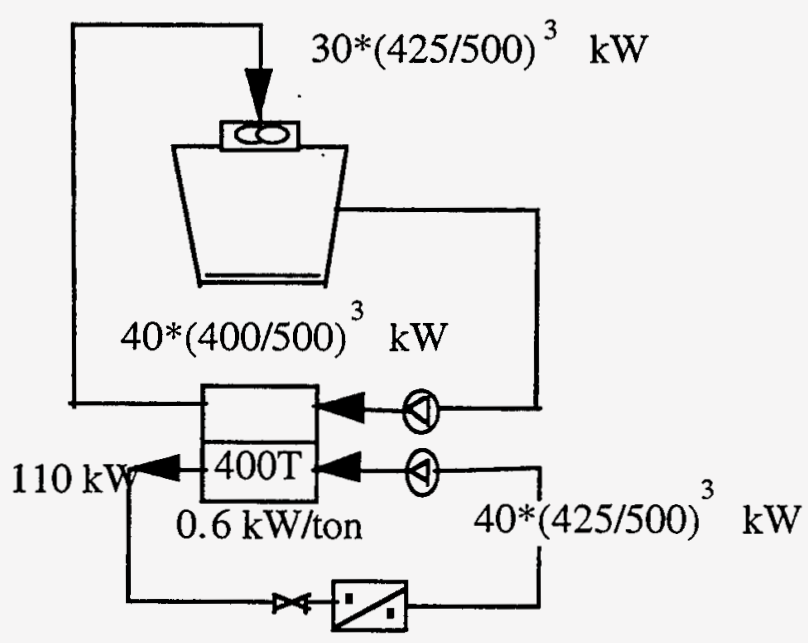

16 Cooling tons are proportional to flow and flow pumping energy is scaled as the cube of flow. Therefore, reducing the chiller size has a dramatic affect on reducing pumping power.

17 This is the cost of $1 \mathrm{~kW}$ for $8760 \mathrm{hrs} / \mathrm{year}$ at $\$ 0.088 / \mathrm{kWh}$. 
Another way to think about the value of high quality data for large cooling plants is to consider cooling energy as liquid money (Houghton, 1996). A 3,000 ton chiller plant represents $\$ 300 /$ hour of operating costs for $1 \mathrm{~kW} /$ ton and 10 cents $/ \mathrm{kWh}$. Therefore, the cost of a $\$ 6000$ magnetic flow meter (first costs plus installation) is equivalent to only 20 hours of operation. With 2,000 hours of full-load operation, a five-percent error in measurement could reach $\$ 30,000 /$ year.

\section{What are the consequences of not sensing?}

Cooling towers provide an excellent example. A large cooling tower has multiple cells, each with its own fan, water balancing valves, and infill. Lee Eng Lock recently conducted a quick study using $\pm 0.1^{\circ} \mathrm{C}$ sensors on the outlet temperatures of an 8-cell tower at SGS-Thomson. As usual, he found unequal outlet temperatures - some cells are not cooling as well as others. This could be due to factors such as slack fan belts, poorly assembled infill (e.g. manual operation in the fill), dirt accumulated in the fill, imbalance of water flow (some cells have excessive water). The tower had been running for years in this condition. Analysis shows that rectifying the defects would enable lower water temperatures, in turn driving down chiller $\mathrm{kW}$. The savings over three years can buy new towers.

\section{Are common sensors adequate for the proposed diagnostics?}

No. The currently proposed system requires sensing of energy, weather and water side variables (temperatures, pressures and flows). Sensors commonly used in buildings are typically not adequate due to durability problems (frequent failures or falling out of calibration), or due to accuracy problems (e.g. measuring flows accurately is crucial, but typical systems either do not measure flow or do so with inadequate accuracy). Less accuracy is needed for day-to-day control than is needed for diagnostics and evaluation of equipment performance. Typical EMCS data are not used for precise measurement of cooling tons or energy consumption. Rather, these data are used for relative control. However, if one approaches a building with an interest in characterizing control strategies, schedules, loads, and efficiency levels, current EMCS data are not reliable.

There are tradeoffs between sensor quality and frequency of calibration. The evaluation of sensors, which is ideally an economic cost-benefit analysis, is complex because it is difficult to obtain cost data associated with servicing, maintaining, and calibrating sensors. Anecdotal evidence from the field suggest that the problems of EMCS sensor calibration are so severe that even monthly efforts to calibrate sensors are inadequate. On the other hand, high-quality sensors that have higher first costs have been shown to function reliably for several years, and up to a decade, with little or no calibration required.

\section{Is sensor calibration a problem in commercial buildings?}

Yes, given the widespread use of low-quality building sensors, calibration is a problem in many buildings. The problems are related to poor calibration during start up and sensors going out of calibration over time. Sometimes, this results in extensive maintenance costs to frequently recalibrate the sensors. Unfortunately, operators frequently "give up" and instruct the control system to ignore the sensor readings.

These problems can be remedied with the use of higher quality sensors, which are commercially available. While first costs are higher, these sensors can have a lower lifecycle cost. Higher quality sensors maintain their calibration for long periods. 
Furthermore, one can use them for better control and fine-tuning that might not be feasible if less reliable sensors are used.

\section{Are adequate sensors available?}

Yes. The system designed by the project team is described in Section 3.7. These sensors have been proven over time in several high-end installations to provide durable accurate data. We provide two examples of the extent of long-term precision from high-quality sensors. The first example is based on the results of multiple installations by Supersymmetry (Lee and Hibberd, 1992). These systems have been used in multiple installations with excellent results for multi-year periods. A second example is based on research on flow meters from Esource. One researcher reported that an existing magnetic flow meter was compared to a new installation, showing it was able to produce reliable flow measurements after ten years of operation (Houghton, 1996). Both of these measurement systems required higher first cost, but resulted in lower life-cycle cost than EMCS-based monitoring because of the reduced maintenance costs.

\subsection{Task D: Define Economic Boundary Conditions ${ }^{18}$}

\subsubsection{Purpose and Methodology of Defining Economic Boundaries}

The purpose of this task was to define economic boundary conditions that could be used to guide the decision process regarding the extent, architecture and features of the proposed diagnostic system. These boundary conditions are our interpretation of the economic criteria that building managers consider important. Plus, we reviewed related research and technology to make sure our approach was not duplicating other research efforts or private sector technology development.

This evaluation was conducted in broad terms since the intent was to focus on the most desirable system features and applications without the luxury of a complete specification (including costs) of all alternatives. In fact, results of this task were used, in part to choose the specific systems for the focus of the diagnostic system. We were concerned with both the economic value of direct energy savings, plus the non-energy benefits further discussed below. Our strategy was to develop a specific list of criteria based on the results of tasks A through $\mathrm{C}$.

\subsubsection{Results of Defining Economic Boundaries}

Eleven criteria were established. These are summarized in five primary categories with the following sub-issues. Each of these criteria were assigned a value of high, medium, or low.

1. Is the $O \& M$ problem addressed by the diagnostic system significant in terms of:

- Complaints from tenants

- Frequent hassles (labor intensive)

- $\quad$ Energy or power consumed

- Dollars consumed

18 There is no appendix associated with this task. All results are given here. 
2. How difficult and costly is it to detect and correct the O\&M or design problem?

- Detect it

- Diagnose it

- Correct it

- Does it require retrofit?

- Does it only require some maintenance?

- Does the correction last?

3. How difficult is it to monitor the specific building system or subsystem?

- Costs for continuous versus periodic monitoring

- What sensors are needed?

- Do the sensors need frequent calibration?

4. Does the diagnostic system or technique provide valuable information?

- Is it difficult to develop information about the quality of the diagnostic output?

- How useful is a data base of archival information about the building (drawings, pictures of system details, even videos)?

- How costly and feasible is it to add automated detection?

5. Does the particular capability already exist for purchase?

- How likely is it that a given capability will be developed by others?

- How large are the economic barriers to developing the system as a costeffective business and service?

The above economic issues assume that the basic technical requirements of the system are met. That is, the data are assumed to be accurate and believable, easy to access, and understandable. Simply meeting these basic technical requirements also has economic value.

\subsection{Task E: Narrow The Focus of The Diagnostic System}

\subsubsection{Purpose and Methodology to Select System Focus}

The results of tasks A, B, C, D and $\mathrm{H}$ demonstrate to the research team that there is a need for competent building diagnostic systems. Furthermore, current installed technology does not meet customer needs. The purpose of this task was to synthesize results from Tasks $A$ though $D$ and select a diagnostic approach and a building system, or set of building systems as the best candidates for development of the initial diagnostic system and evaluation of its practical feasibility.

The concept was to identify the most promising building systems for which we could develop a conceptual framework for a diagnostic system. This diagnostic system should evaluate the regimes in which the chosen system is performing correctly or malfunctioning. 
The decision on what to include in the system was affected by all aspects of the problem: users (Task A), methodologies (Tasks B and C), economic conditions (Task D), and the capabilities of modern information hardware and software (data loggers, communications, storage, computing and display). How this was done is discussed in detail in Appendix E. Here, we provide a summary of the method and a detailed description of the results.

The methodology followed in selecting the building systems for analysis was to apply the criteria presented in the previous section and those discussed in Appendix E to combinations of major building systems and alternatives for their diagnosis in order to select the most appropriate one(s) for the Phase 2 demonstration. This involves a systemic choice involving both the building components to be addressed and the diagnostic architectures to be used. Candidates for the former included, for example, whole-building, lighting, ventilation, and cooling (chiller, towers, etc.) systems. Candidates for the latter included, for example, bottom-up/top-down and human assisted versus automatic approaches. The original supposition was that we would choose a single test-case subsystem or component, such as an air handler, for explicit diagnosis. Instead we have taken a broader approach described below.

\subsubsection{Results of Selecting the System Focus}

Our conclusion from the previous tasks was that the diagnostic system should be designed as a top-down analysis tool, rather than a bottom-up approach. The top-down approach is based on identifying "high-level" and gross operating deficiencies. We have determined that this approach meets today's market needs. Innovative building operators have expressed a great interest in trying to better understand how to operate their cooling plant and how to evaluate its energy performance. The operators we've been talking to want an open information system, not a black-box automated approach. The selection of the focus for the top-down system was based on results of the operator interviews and several other issues discussed below.

By contrast, bottom-up diagnostic systems are based on extremely detailed descriptions of specific building equipment. These descriptions are the basis for most of the diagnostics research, which uses training statistical models with limited data sets and testing those models for the ability to detect various categories of faults. Our approach can be likened to the medical analogy ${ }^{19}$ of first going to a general practitioner prior to visiting a specialist. We concluded that there are important benefits of looking at the various levels of information to diagnose the most important building performance problems. However, we also were committed to diagnosing a single system in detail. As seen below, we concluded that the cooling tower was the best candidate. Another benefit of the proposed approach is that it forms the foundation of a training tool for operators to better understand the major energy-consumption patterns in their facility. The three levels and associated systems chosen for the diagnostic system are the following (as shown in Figure 6):

Level I. Whole Building (Aggregate performance)

Level II. Major End-Use and Systems (Cooling)

Level III. Component (Chiller and Cooling Tower)

19 The authors first heard this analogy in a talk by Peter Herzog. It is very suggestive of the diagnostic situation in buildings. 
Figure 6: Three Levels of the Diagnostic System

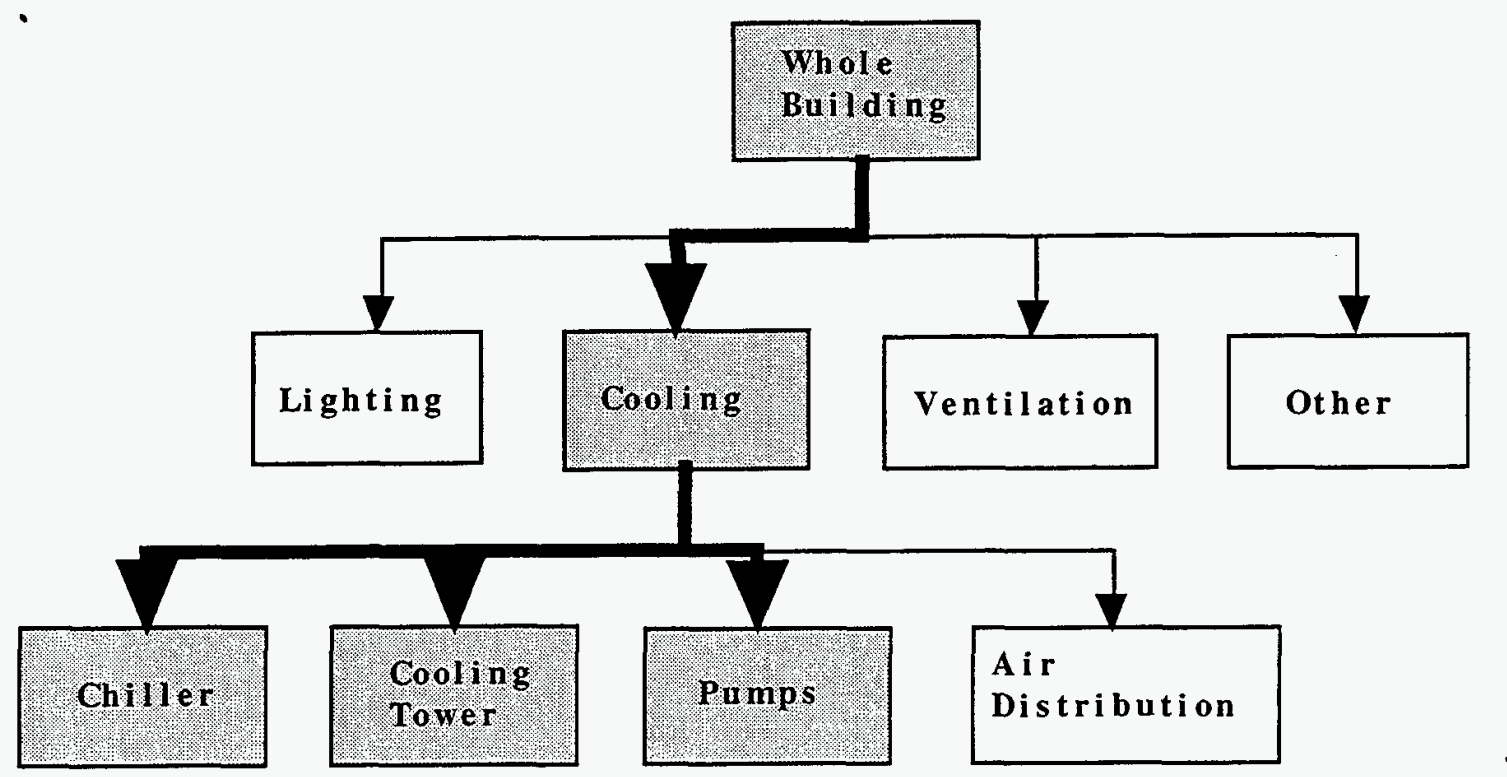

The rationale for the selection of these systems is as follows. First, the selection of whole-building diagnostics is the starting point of the proposed diagnostic system. Whole-building data contain the basic yard-sticks by which a building operator can get an overall set of metrics to evaluate building performance. These specific metrics are described in the discussion of Task F. Most importantly, the whole-building energy costs are determined with these data.

The rationale for the selection of the cooling system is related to the benefits of working with this system, plus the difficulties related with the competing systems of lighting or ventilation systems. First, we found that there can be a major improvement in cooling plant analysis with the addition of improved metering equipment, such as thermistors and magnetic flow meters. With the addition of these systems, we will characterize the energy efficiency of the cooling plant. Chillers are the largest single energy-using components in large office buildings, and are thus one of the most logical items to evaluate. Evaluating the entire cooling plant will allow us to understand the overall system performance, which is more important than examining a component in isolation from the system.

For comparison, the measurement issues associated with ventilation and lighting are more physically distributed throughout a building. Measuring air flows is particularly problematic. A similar confounding issue with ventilation systems is that ventilation requirements in individual zones vary because of duct configurations and thermal variations. The result is that ventilation systems are difficult to evaluate, and are complex because they are coupled to tenant comfort and indoor air quality issues. These were determined not to be good candidates for the initial demonstration, but are suitable for future research. (CIEE has extensive related research on thermal distribution systems and is interested in ventilation and air quality.) Our initial diagnostic system, by contrast, is restricted to monitoring cooling plant equipment that is located either in the central plant or on the rooftop. We are not including air side, ventilation, or other thermal distribution systems in our analysis during currently planned phases. These systems include air handlers, ducts, and zonal fan systems and even the chilled water supply loops that may reach out into zones. 
The components selected for the analysis are chillers and cooling towers. Both of these components were targets of complaints from building managers as subjects of poor sizing. Chillers are often oversized, thus they require more power per ton than optimal because they are less efficient at low partial load. Cooling towers are often undersized. Larger towers allow the chiller to operate at cooler condensing temperatures. The diagnostic system will explore major failure modes for these components, as further described in the following task summary (Task F).

The team plans to develop a permanently installed and continuously active system. This is necessary because buildings continuously change. For example, some problems reoccur, such as those from modifications to schedules to handle special events. These modifications often lead to equipment being left on when not needed. The diagnostic system is designed to operate in parallel with any existing EMCS, rather than expanding or modifying the EMCS. This decision was made because current EMCSs do not have the necessary capabilities in sensing, network capacity, frequency of sensing, data archives, data processing and visualization.

Again it is useful to emphasize how the proposed diagnostic system differs from previously developed systems. The top-down information system allows an operator to gain quick access to key performance metrics and standardized plots. This information system is linked to an automated data acquisition system to allow for automation of the data collection. These two last sentences are the heart of the project, and are unique aspects of the project. Again, as mentioned, related approaches that are known for being easy to use are built around short-term rather than continuous monitoring systems. Our diagnostics approach stands in sharp contrast with bottom-up approaches that attempt to diagnose all possible modes of performance failures.

\subsection{Task F: Conduct Failure Mode Analysis}

\subsubsection{Purpose and Methodology of Failure Mode Analysis}

As discussed in detail in Appendix F, the purpose of this task was twofold. First, we were to assess the major modes of failure for the selected building systems. Second, we were to evaluate the diagnostic techniques applicable to detect and diagnose the modes of failure.

The methodology we used involved four elements. First, we defined the most important performance metrics and associated benchmark data to characterize the fundamental principles of how the performance can be characterized. Second, we developed a series of standard graphics that will allow the metrics to be displayed in a manner that assists in the diagnosis. These graphs were analyzed to determine benchmark signatures for good performance, such as where measured values should fall on a given analysis plot, or what the curve shape should look like if the system or component is performing properly. Third, we developed a series of measurements and sensing requirements to evaluate the systems and components. Fourth, we listed common modes of failure that one can diagnose with the given metrics and graphics based on case study data and related literature. The discussion of failure modes is not an entirely exhaustive list of failures, but covers common and critical modes of failure. In most of these categories, we have used the following relationship to search for efficiency increases (i.e. detect problems). There are three categories of deficiencies: efficiency degradation, scheduling, and load issues. For example, in a chiller system, these three categories can be summarized by: 


$$
\mathrm{kWh}=\mathrm{kW} / \text { ton (efficiency) } * \text { tons (load) } * \text { hour (schedule) }
$$

For each level in the hierarchy, a step by step diagnostic procedure was developed.

\subsubsection{Results of Failure Mode Analysis}

This section includes a brief discussion of the metrics, graphics, and failure modes for each system and component for the diagnostic system. Detailed results are given in Appendix F. The proposed knowledge base is designed to be modular, with a set of standard graphs and standard information. These graphs also serve as a tutorial that is designed to orient the building operator on how best to understand the system or component's energy performance.

\section{Whole Building}

As mentioned, whole-building data are critical elements of a top-down system, allowing an operator or building owner to evaluate the annual energy use and annual energy costs. For comparison with other buildings, these data are typically normalized by floor area, to produce an energy-use intensity (EUI). As examples, we present two sample diagnostic plots at the whole building level. In Figure 7, benchmark whole building EUIs are plotted for comparison with a given actual building. Data sources for this plot include: EIA, 1994, Akbari et al, 1993 and 1989, Piette et al, 1986, and Energy User News, 1995. One compares these values with those of the current building to determine whether large differences exist. Independently, or as an adjunct to results from Figure 7, one can detect and diagnose time of day usage problems with three-dimensional, hourly wholebuilding, carpet plots such as seen in Figure 8. Excessive off hour use can be easily detected with such plots. Given a reasonable data base query capability, one could also, for example, limit plots like Figure 8 to weekends and holidays to sharpen the focused search for off hour consumption.

\section{Figure 7: Office Building Annual Energy Use Intensities for Comparison with a Given Actual Building.}

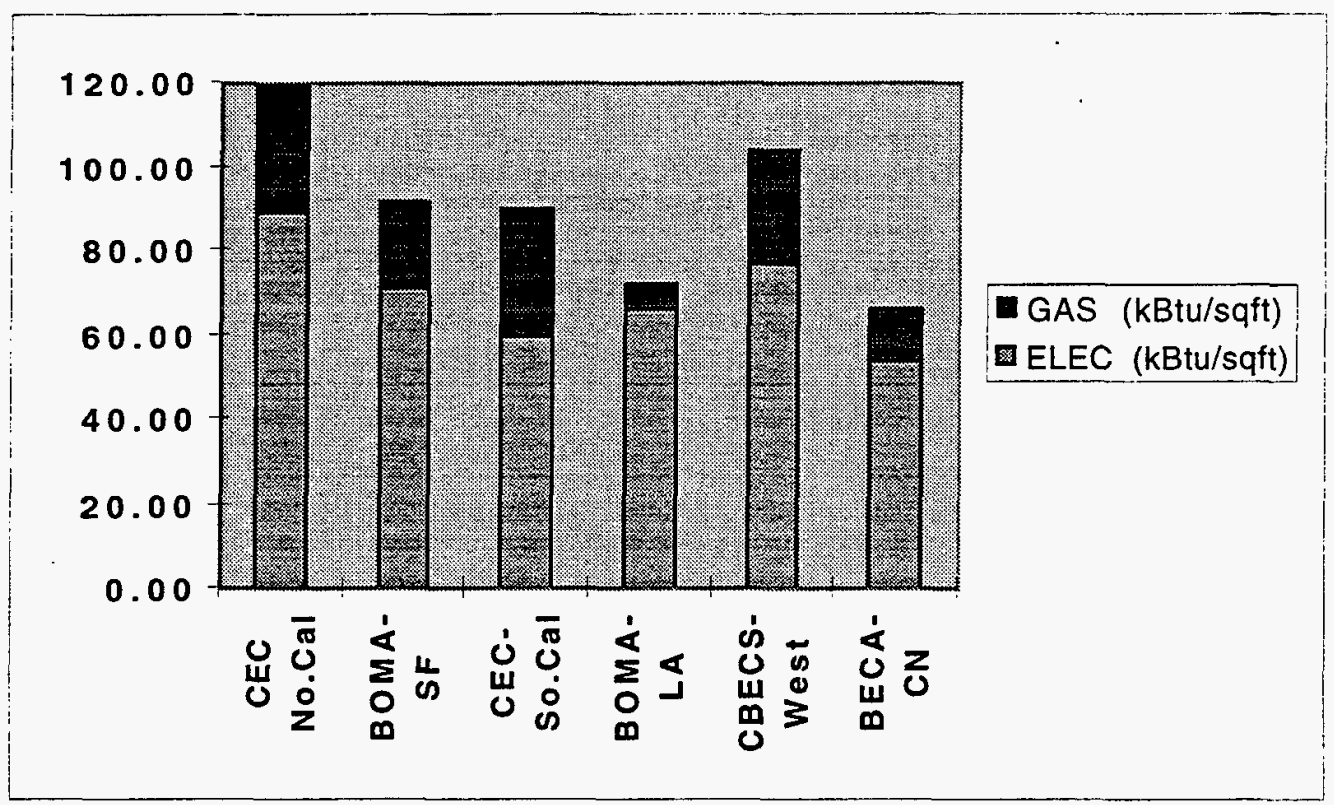


Figure 7: Three-dimensional, Hourly Whole-Building, Carpet Plot.

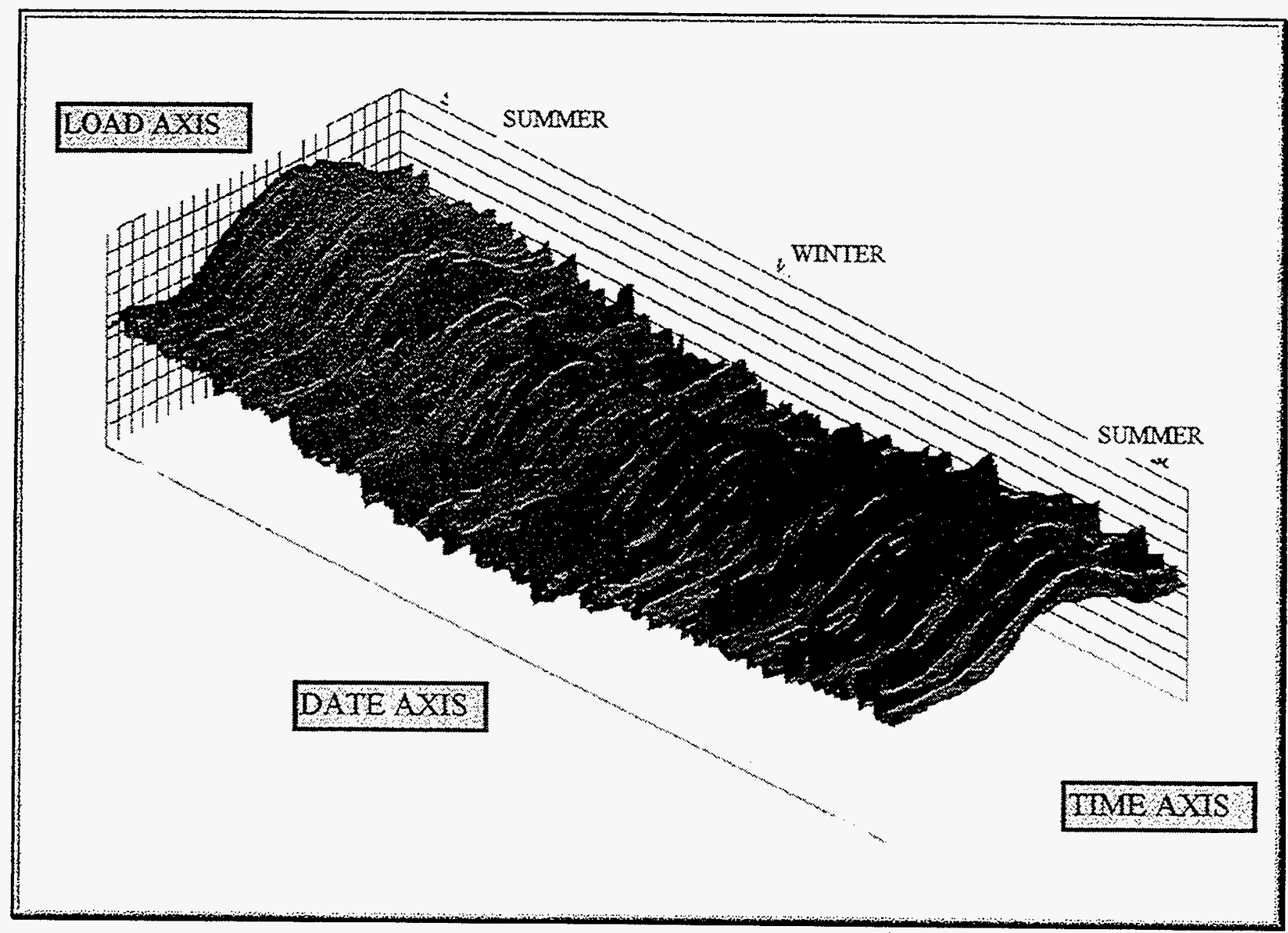


Examples of key failures that can commonly be identified with whole building hourly data include:

- Start-up peaks - such as high peak demands from six AM. to nine AM that are substantially greater than average daytime peak demands. Start-up peaks are common because equipment are scheduled to cool down or heat up building thermal systems without careful sequencing.

- High afternoon peaks - similar to start-up peaks, peak demands may creep throughout the afternoon. Careful tracking of these peaks can help reduce peak demand charges.

- High loads at night - one of the most important energy savings opportunities in buildings is to identify equipment that is on at night when it is not needed.

\section{Cooling System}

The entire cooling system efficiency can be evaluated using the efficiency versus load analysis (kW/ton vs. cooling tons) as an important element of the Knowledge Based System (KBS). A given building will fall somewhere on the continuum depicted in Figure 9 . The intent is to move it to the right as far as is economically appropriate.

Figure 9: Context Associated with Defining Benefits of the Diagnostic System.

System Efficiency

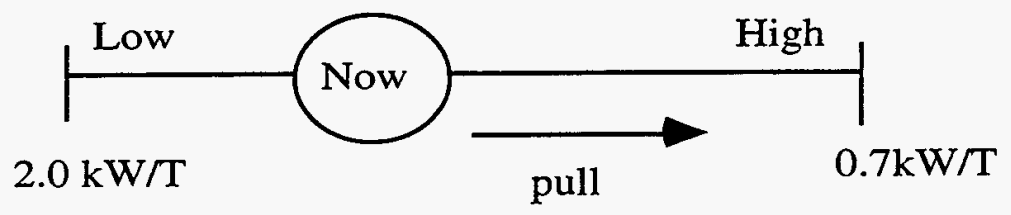

These data will be generated for the Phase 2 case study buildings, and the efficiency versus load graphics will be compared with the theoretical shape. The total cooling system performance in $\mathrm{kW} /$ ton is affected by the $\mathrm{kW} /$ ton for each component. As seen in Figure 10, it is convenient to view the entire system performance as a series of plots for each component, each showing the $\mathrm{kW} /$ ton vs. percent load. The shape of the efficiency versus percent load curve is dominated by the chiller, so the entire cooling system $\mathrm{kW} /$ ton curve tends to look like the chiller curve. 
Figure 10: Cooling Plant Performance.

\section{Cooling Plant Performance}

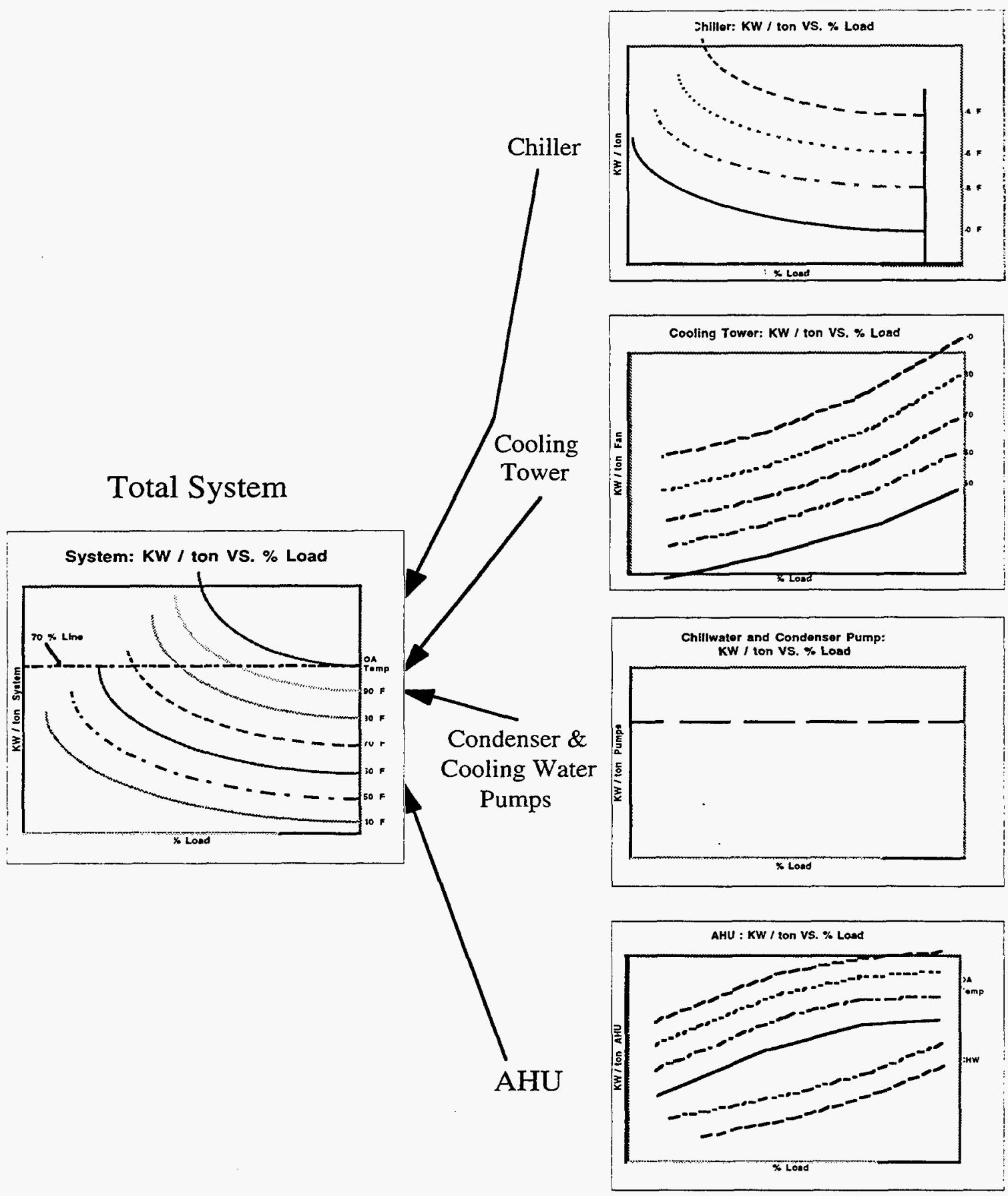


Examples of cooling plant failure modes are the following:

\section{Efficiency Degradation}

- Deviation from Manufacturers Specifications because of Design Flaws

- Deviations From Historical Performance (e.g., cooling tower down time )

- Poor Water Flow (resulting in need for multiple chillers)

- Chiller Component Malfunctions (e.g., condenser fan cycling)

- Fouling

- Inappropriate Refrigerant Charge

Schedule and Control Deficiencies

- Excessive On Time

- Short Cycling

\section{Load Issues}

- Poor Full-Load or Part-Load Performance (e.g., weather correlation)

- Component Oversized or Undersized

Failure Modes Detected with Condenser and Chilled Water Flow Data

- Low Flow

- Flow Not Varying.

Failure Modes Detected with Cooling Plant Temperature Data

- Improper Setpoints

- Sub-optimal Chiller Controls

- Poorly Calibrated or Poorly Located Thermostats

\section{Chiller}

The classic example of chiller diagnostics is depicted in Figure 11. Here, efficiency ( $\mathrm{kW} /$ ton) is plotted versus load (tons). Chillers should ideally operate near their rated efficiency (purchase point). Various problems (oversizing, improper scheduling, control problems etc.) exhibit signatures on this type of plot. The failure modes for chillers are similar to those listed for cooling systems. 
Figure 11: Chiller Efficiency (kW/ton vs. tons).

Efficiency (kW/ton)

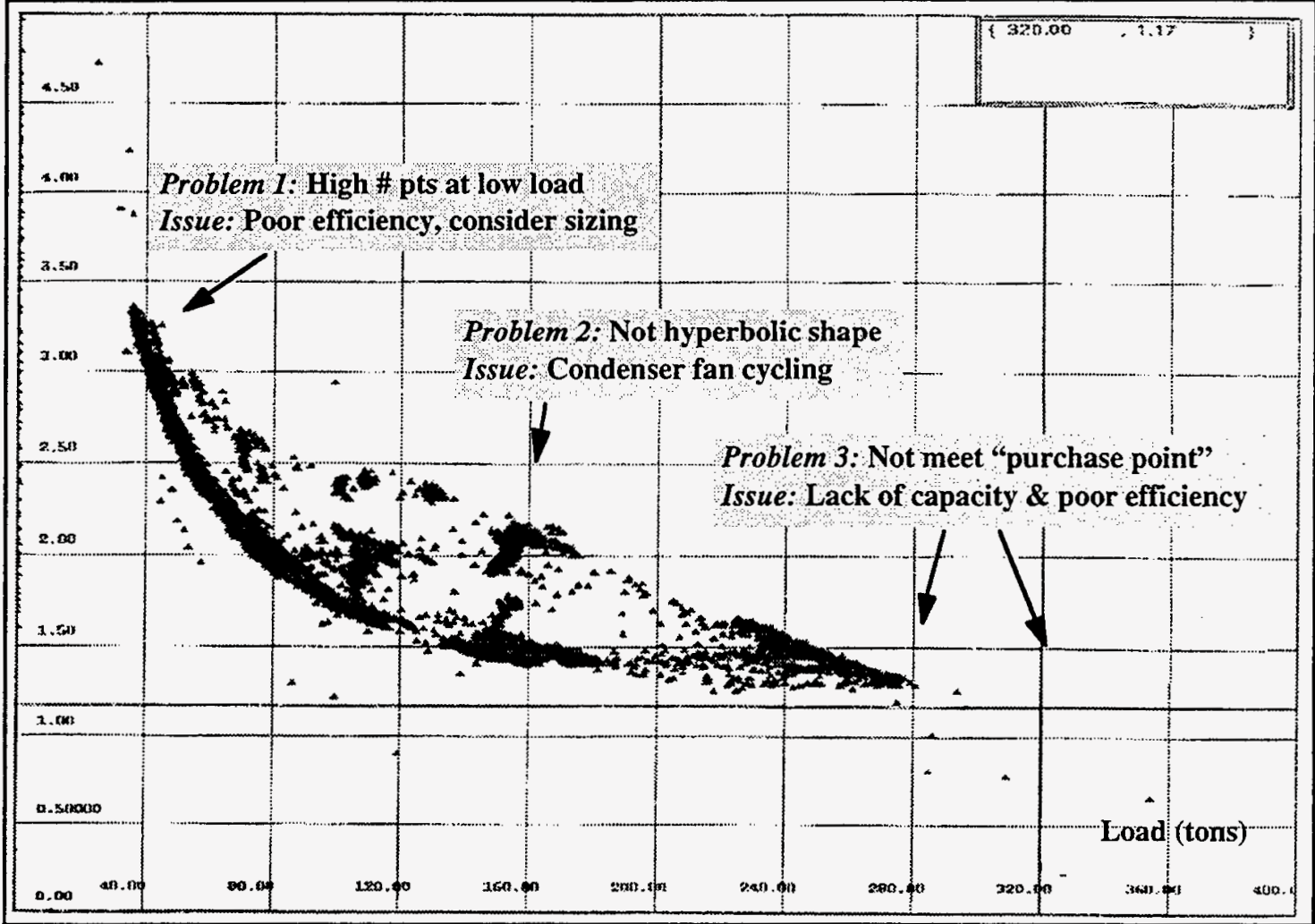

\section{Cooling Tower}

Figure 12 shows a typical manufacturers plot of cooling tower performance. This plot is for one flow rate; cooling towers and chillers typically are designed to operate at a single flow rate. For this flow rate, the temperature of the water off the tower is a function of the wet bulb temperature and the range. Plotting the actual temperature of the water off the tower for a given flow rate, range, and wet bulb temperature can help identify possible problems with capacity. 
Figure 11: Typical Manufacturers Plot of Cooling Tower Performance and Manufacturer's Specifications

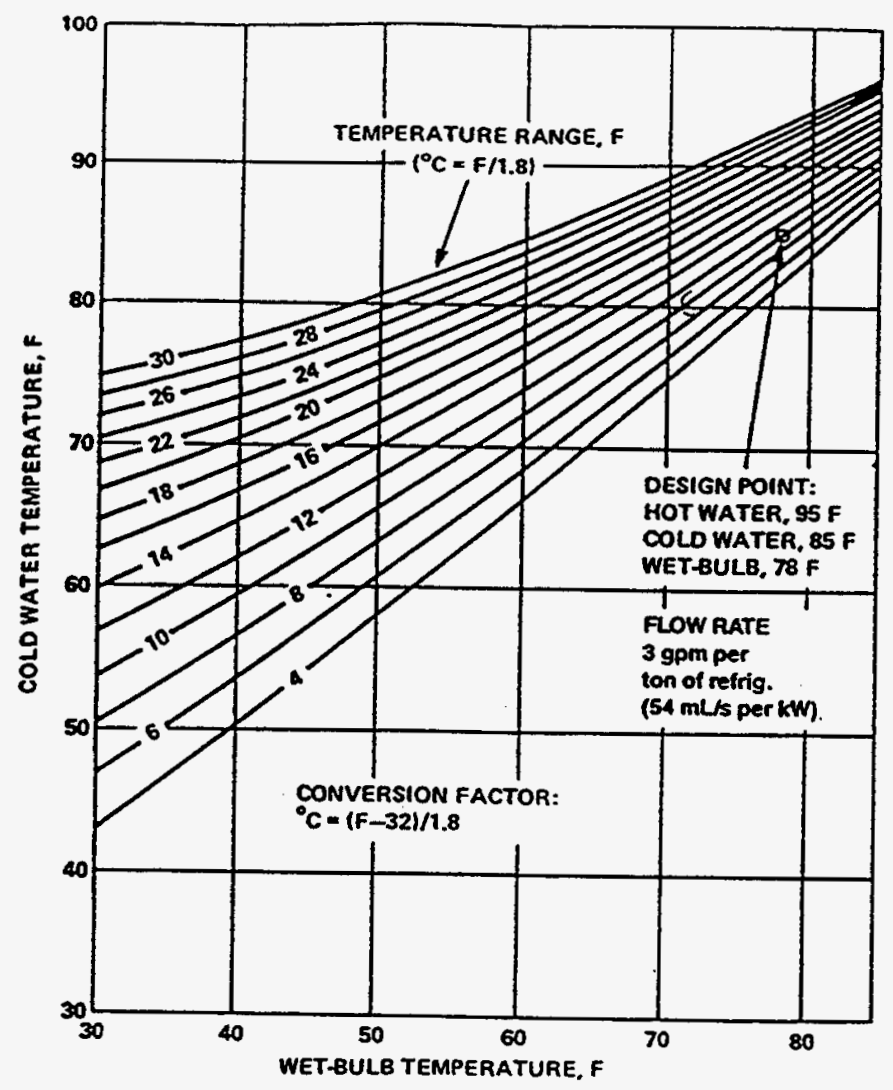


Common cooling tower failure modes are as follows:

\section{Efficiency Degradation}

- Fouling - Under capacity occurs when the cooling tower fill or nozzles become fouled. When this happens, the effective capacity of the cooling tower is reduced.

- Insufficient Flow - If the cooling tower is fouled, there will be insufficient water flow.

- Excess Flow - Excess flow is also a problem in cooling towers, resulting in inefficient operation of the pumps.

- Loss of Approach - Another symptom of a fouled cooling tower is loss of approach, where the tower is unable to provide water at a temperature that is as close to the wetbulb temperature as it was designed to do.

- Range not Achieved - Often if the tower is clogged or fouled, or the fill is otherwise not performing fully, the designed temperature range will not be achieved.

- Too Few Cells Running - Since equipment such as chillers and pumps carry a penalty for operating below full load, it is not uncommon to extend this philosophy of staging to cooling towers, and run only the number needed, as fully loaded as possible.

- Recirculation - Recirculation refers to a condition where, due to the geometry of the enclosure for the cooling tower and adjacent structures, and the relative wind directions, hot saturated air leaving the cooling tower is reintroduced into the tower inlet. Obviously, this reduces the performance of the cooling tower

\section{Load}

- Tower Under Capacity - A common problem in cooling towers is that they are undersized or have insufficient capacity. Since the size of the tower is directly related to capital expenditures, it is common to undersize them, and to ignore the improvement in chiller performance that is realized when the cooling tower is properly sized.

\section{Schedule and Control}

- Tower not Modulating

- Tower not Interlocked - The cooling tower operation should be interlocked with other parts of the cooling system.

- Suboptimal Water-Loop Temperature Control - One common failure is to have suboptimal control of condenser temperatures.

\section{Miscellaneous Design Errors}

- Pump Inlet Design Error - In one of the commissioning studies, there was a cooling tower pump water problem because the location of the pump inlet was above the tower sump level, causing the motor to burn out, and the backup pump to run.

The sensor descriptions and accuracy requirements for these measurements are presented in Table 4 on page 35 . 


\subsection{Task G: Evaluate System Requirements}

\subsubsection{Purpose and Methodology to Evaluate System Requirements}

The purpose of this task was to evaluate the requirements for the diagnostic system. This included requirements for sensing, archiving, data communication, computational speed, data storage, and displaying results. Analysis techniques, benchmarking and comparison data needs were also considered. After the project scope was narrowed, we developed such a list. This task involved synthesizing results from the previous tasks to generate the description of the system's technical requirements. Further results are given in Appendix G.

\subsubsection{Results of Evaluation of System Requirements}

As a result of the work on previous tasks and trends in the computer market yielding falling prices on disk storage, data networks and processor speed, we determined that it was most cost effective to build a knowledge base on a UNIX platform with local stations to provide reliable information to building operators and their financial managers and remote stations for use by the researchers. This proposed hardware and software configuration, which are based on readily available technology, includes the following:

Sensors: The proposed system consists of 85 monitoring points including high-grade thermistors, power meters, magnetic flow meters, aspirated psychrometers, and a variety of similar monitoring systems, with data archived every minute. All of this sensor technology has been proven in the field. The monitoring equipment is listed in Table 4, and a detailed description of the instrumentation is given in Appendix G.

\section{Table 4: Systems and Sensors of the Diagnostic System.}

\begin{tabular}{|l|l|l|}
\hline \multicolumn{1}{|c|}{ System to be Evaluated } & \multicolumn{1}{|c|}{ Sensor Type } & \multicolumn{1}{c|}{ Accuracy } \\
\hline Whole Building & Power & $+/-0.25 \%$ \\
\hline Chillers & Differential Pressure (water) & $+/-0.25 \%$ \\
& Water Temperatures & $+/-0.25 \%$ \\
& Flows (water) & $+/-1.00 \%$ \\
& Power (to chillers) & $+/-0.25 \%$ \\
\hline Pumps & Differential Pressure (water) & $+/-0.25 \%$ \\
& Power & $+/-0.25 \%$ \\
\hline Cooling Tower & Dry Bulb Temperature & $+/-0.25 \%$ \\
& Aspirated Psychrometer & on-site calibration \\
& Water Temperatures & $+/-0.25 \%$ \\
& Power & $+/-0.25 \%$ \\
& Flow & $+/-1.00 \%$ \\
\hline Local Micro-Climate & Dry Bulb Temperature & $+/-0.25 \%$ \\
& Aspirated Psychrometer & on-site calibration \\
\hline
\end{tabular}

Figure 13 through Figure 15 show schematic representations of the monitoring plans for the chillers and cooling towers. The chiller monitoring will capture key parameters in the chiller operation such as water flows and temperatures, pressure drop, and power. These data will allow determination of chiller efficiency and loads. We will also measure the pressure drop across the chiller heat exchangers to determine the extent of fouling. The cooling tower monitoring will also include water temperatures and flows, plus local 
outdoor air data and cooling tower fan power. The local outdoor air data are an important factor in assessing the performance of cooling towers. A temperature measurement station including an aspirated psychrometer will be installed on the top of the building as far away from the cooling towers as possible. Data from this psychrometer will be used to evaluate "nano-climate" effects. Cooling tower intake conditions will be compared with outdoor air conditions to evaluate recirculation of cooling tower exhaust.

Data Logger: A stand alone data logger, including cables and 16 bit A/D converters, hard drive and a PC to control it. This data logger will be networked to the UNIX stations.

Data Communications and Storage: There are several ways to collect and store the data. If one simply stores the A/D bits, one year of data will require approximately 90 Mbytes. Alternatively, if one chooses to archive in 4 byte reals, one would need twice as much (180 MB). The sensors are hard wired, and will be converted from analog signals to digital signals with a 16 bit $\mathrm{A} / \mathrm{D}$ converter.

Database and Visualization: Figure 2 is a depiction of the components of the proposed diagnostic system. The data base is needed to correctly archive and retrieve desired information from the large amount of data. The advanced graphics and powerful computing environment are needed in a prototype system like the one proposed to implement desirable data computation and visualization without constraints imposed by the computing platform. This is both a hardware and a software issue. We intend to use UNIX graphics workstations ${ }^{20}$ and a modified form of the Electric Eye building data visualization software. Changes in the software include addition of curves described in Appendix F (especially regarding the cooling tower and cost/benefit analysis).

Commissioning: The diagnostic system will need to be commissioned. This will be done by an integrated effort involving both the team and the building personnel. This is actually part of the training described below, in that it will make the building personnel even more familiar with the system and how it works.

Training: Building personnel are intimately involved with this project in that they will install the system (sensors, communications links etc.) and be intimately involved in its daily use, the proposed system also involves substantial operator training. As seen in Appendix F, it is crucial that building personnel be trained in the technical approach underlying the diagnostic system ("What is the best way to visualize whether building systems are delivering desired performance?") and the use of specific diagnostic graphs.

Remote Monitoring: The proposed system also envisions several remote monitoring sites. There will be a graphics workstation with full access to the system's data at each team member's home site. Additional sites may be located at interested sponsors' locations. 
Figure 12: Chiller Monitoring Schematic

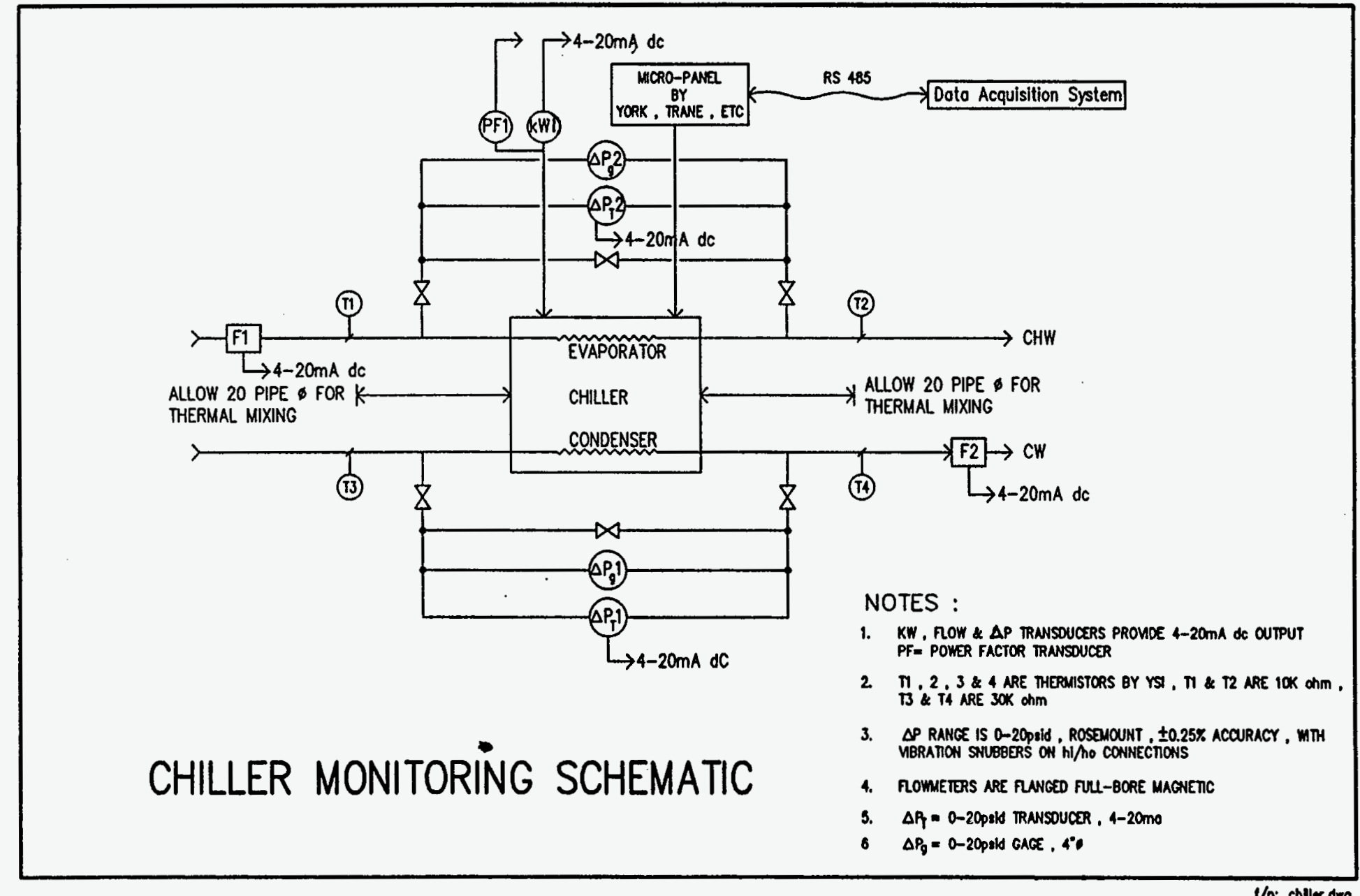


Figure 13: Micro-Climate vs. Nano-Climate Measurement Schematic for Cooling Towers

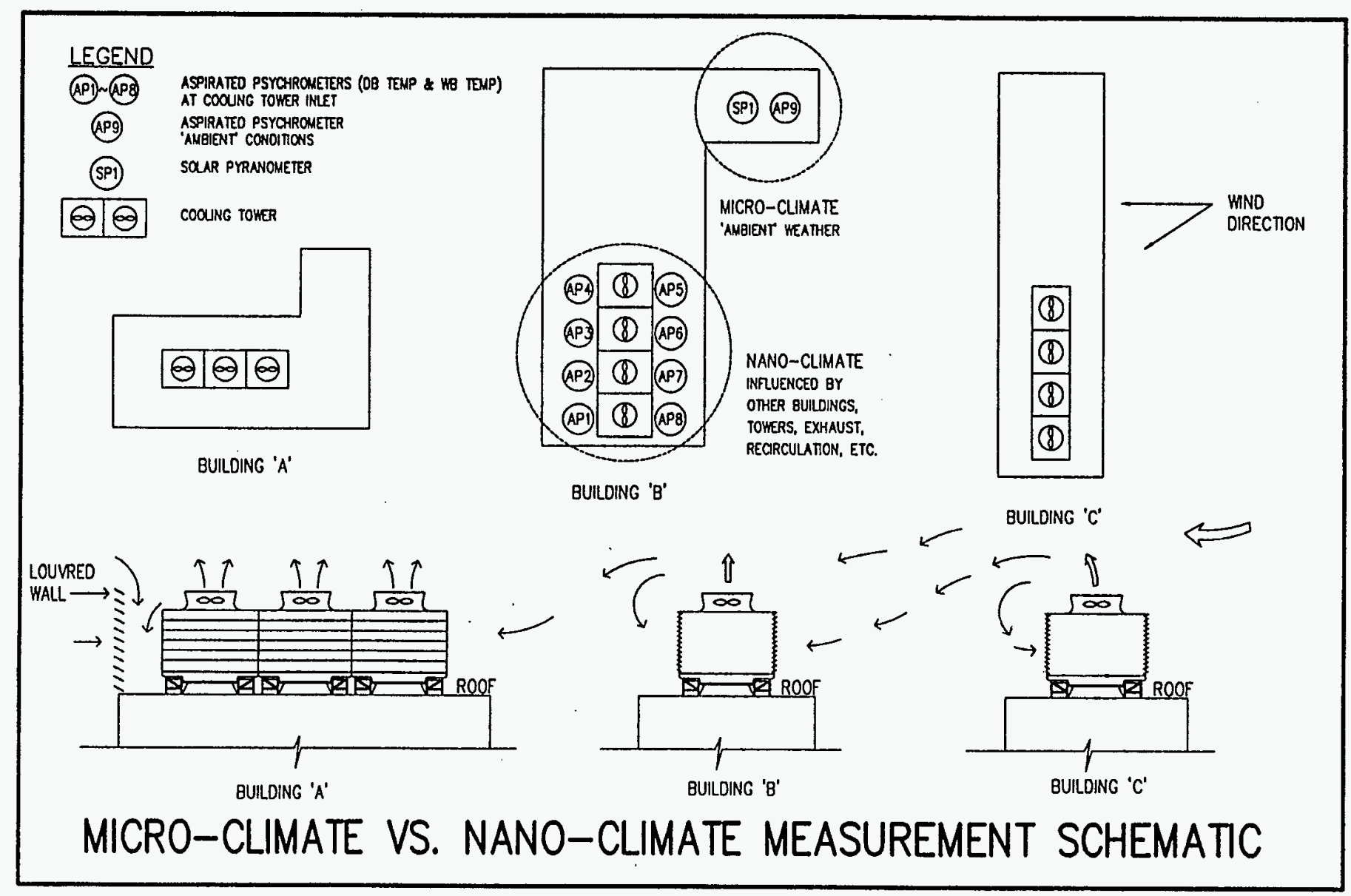

t/n:micrlim.dwg 


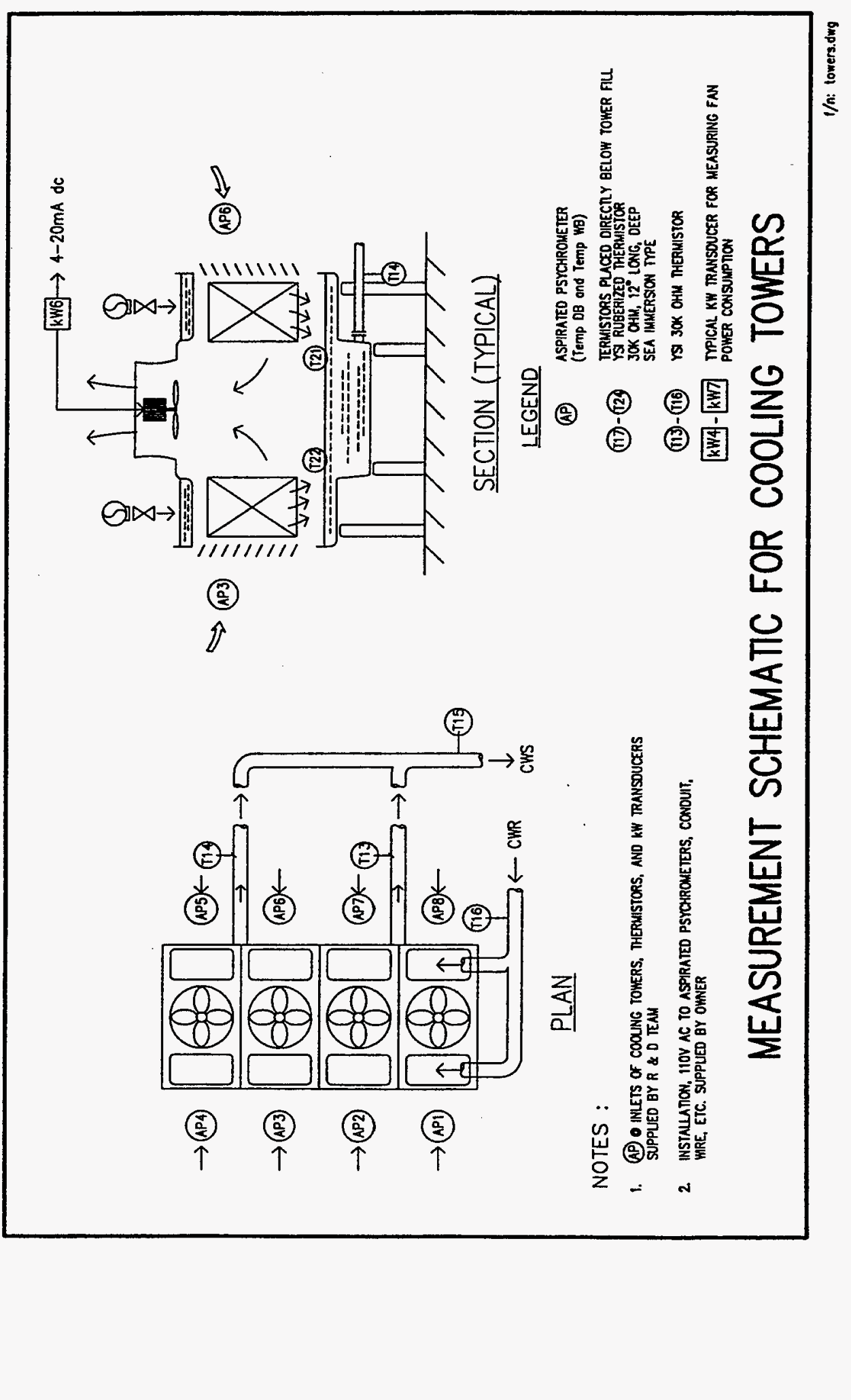




\subsection{Task H: Contact Control Industry}

\subsubsection{Purpose and Methodology of Industry Contact}

The purpose of this task was to contact control manufacturers to evaluate related activities and their potential interest in collaboration. One method we used to evaluate the potential for collaboration with control companies was to obtain feedback from building operators about current and emerging control technologies and services. The second method was to contact control companies directly. We contacted several companies, including R\&D offices, local service managers, and service technicians. Nine control companies were contacted, which included the largest companies. Many additional informal contacts were made during conferences and workshops.

\subsubsection{Results from Industry Contact ${ }^{21}$}

\section{Control Industry Feedback and Market Status.}

As mentioned above, current EMCSs do not support the capabilities of the diagnostic system that the team has proposed. However, there is much interest by control companies in working with the team to provide systems of the type envisioned in this project. Neither large nor small vendors expressed a position that the CIEE technical approach is inadequate. Some expressed concerns that customers don't exploit the capabilities in current systems or that customers would not pay the added amount for the capabilities we are proposing.

Manufacturers are understandably reluctant to discuss their future products because of industry competition. Most manufacturers suggest that they will develop more advanced measurement, archiving, analysis, and diagnostic systems when the building owners request these capabilities. Our conclusion is that manufacturers could provide the technologies proposed here. However, it is unlikely that they will provide such capabilities without a fundamental demonstration of the value of more sophisticated information systems. Control companies report that the power of today's EMCSs are often untapped. The controls vendors attribute this to a lack of trained personnel and a lack of understanding about the value of the systems.

The stagnant California economy has created strong competition in the downsized construction market, resulting in more pressure to lower first costs for controls. Large and small vendors report that customers demand an increasing level of service with more features for which they are unwilling to pay. They claim that some low quality vendors are pushing the market in the direction of poor quality at less than profitable prices. Some of the smaller vendors inform us that there are no difficult technical problems impeding their provision of a rudimentary diagnostic (EMCS) system to commercial owners. Small companies with lower costs can underbid older established companies, which creates an unstable business environment. The competitive state of the controls industry and the owner's desire for lowest first cost appear to be related to the industry's apparent lock step development of new features. One R\&D vendor's representative suggested that his company cannot afford to be either ahead or behind their competitors' technical capabilities. This limits innovation, and suggests that major improvements in diagnostic capabilities will be slow in coming to the marketplace. Thus, research projects

21 See Appendix $\mathrm{H}$ for a detailed discussion. 
such as this one are important in spurring the market and demonstrating the value of advanced information systems.

Another important finding mentioned above was that building owners and operators expressed dissatisfaction with many of the large control companies. For example, new direct digital control technology is sometimes seen as confusing and expensive. Building owners and operators also expressed dissatisfaction that many control systems use closed, proprietary "black-box" technology that is not only difficult for them to understand, but is expensive to maintain. Closed systems are expensive to maintain because these systems can often only be serviced by the control company's service representatives, thus the building manager enters into an expensive service contract. The preferred mode of operation in a large Class $\mathrm{A}$ building is to minimize outsourcing so as to develop strong in-house technical support.

Given this situation, we decided not to directly involve the controls industry in partnering to develop the initial system to be deployed in the research project. This will allow us to evaluate how independent information provided from our diagnostic system compares to that from the EMCS at each case-study building. We plan to archive EMCS data for direct comparison with that from the diagnostic system. This is not always possible because of difficulties accessing the data. However, in order to accomplish this, we may need help from the EMCS vendors in the building(s).

\section{Collaboration for Phase 2.}

The research team has a strong interest in having representatives from the controls industry involved in the Project Advisory Committee (PAC). The Market

Transformation report contains further details on the role of the controls industry in our technology transfer efforts. We also intend to develop a relationship with controls and EMCS vendors represented in the buildings chosen as test sites in the demonstration phase. The proposed relationship is to provide the team with technical support to assist in accessing and processing data from an EMCS and providing the technical review and comment.

\subsection{Task I: Summarize Results}

The purpose of this section is to summarize findings from the previous tasks. The discussion below is a summary of the outstanding features of the proposed diagnostic system. Detailed information on each topic is given in the Appendices. In particular, the underlying knowledge base is discussed in detail in Appendix F. The instrumentation plan is detailed in Appendix G, while Appendix I assesses the market transformation options.

\subsubsection{Knowledge Base Diagnostic System Design}

The CIEE Diagnostics project team recommends that a top-down, three-layered diagnostic system described in Tasks $\mathrm{E}$ and $\mathrm{F}$ be developed and demonstrated in Phase 2. The first layer evaluates whole building consumption. The second layer evaluates the cooling end use. The third layer evaluates two subsystems: chillers and cooling towers. (See Figure 6 for a graphical representation.) Diagnostic analysis has been organized as a knowledge base consisting of the following elements:

- Measurement plan, which includes criteria for raw data collection (sensors and metering schematic), plus the data archive and retrieval system. 
- Algorithms and software to convert raw data to more relevant data, such as efficiencies and loads. This will include psychometric analysis, weather sensitivity analysis, and similar diagnostic techniques.

- A standard set of diagnostic plots.

- Benchmark values for typical and best-practice, such as EUIs, efficiencies, and loads (which will be incorporated into the data visualization system).

- Data visualization software.

- Economic analysis to evaluate energy costs by level (whole-building, cooling system, and components) and energy savings from O\&M improvements and retrofits.

\subsubsection{Summary of Objectives and Approach}

The primary objective of the diagnostic system is to introduce state-of-the-art building monitoring and diagnostic information systems into Class $\mathrm{A}$ buildings for use by sophisticated building operators. This objective is based on our background research, which suggests that the proposed system meets the needs of operators and that they support the system we've designed. The concept is to deploy a permanent system to assist in continuous improvements in $O \& M$ to reduce energy use and operating costs. Our overall goal is to work with building owners and property managers in demonstrating the cost effectiveness of the proposed diagnostic system, thereby creating a market demand for such technology. We hope to demonstrate that the system could be cost effective when commercialized by the private sector.

The Phase 2 demonstration is oriented toward deploying the basic infrastructure for an advanced information system, including field tests of initial applications. These demonstrations will allow the controls industry to evaluate the value of such systems that greatly exceed today's current EMCS technology. Such a system is the starting point for more advanced, automated diagnostics, such as those based on fuzzy logic or neural networks. Our approach is to design the system as a rich, interactive information tool that will allow the operator to inquire about how well the building, system, or component is performing.

Our approach stands in contrast to the traditional failure-mode analyses, which are based on a bottom-up approach to identify all possible faults and generate statistical tests for single faults. One problem with this approach is the occurrence of double faults, which also must be considered explicitly. We have not chosen this approach for three reasons. First, it is the subject of ongoing research lead by the International Energy Agency (Hyvarinen and Kohonen, 1993, and Hyvarinen and Karki, 1996) and others, which we do not want to duplicate. Second, we believe our approach will provide more valuable information to building operators more quickly. Third, the approaches compliment each other, and we will be able to incorporate the IEA project results into our design in the future.

Our approach is also different from previously developed top-down or short-term monitoring systems in several ways. It is specifically targeted toward sophisticated building operators and engineers. The fact that it is being developed for these advanced users is unique. Most related research efforts or related techniques are targeted toward an expert user. Related approaches that are known for being easy to use are built around short-term rather than continuous monitoring systems. The proposed monitoring system is based on laboratory-quality instrumentation that is far more reliable, believable, and robust than found in other permanent commercial building systems. 
The diagnostic system will include metering various building systems and components to provide feedback on building performance. The users of the system will be building operators and property managers. The suppliers could be electric utilities, other thirdparty experts such as ESCOs, or control companies. The service would ideally be paid through savings in the operating budget. This technology gives the owners and managers a quantum leap in improving management in their buildings. It could reduce operating costs and make their spaces potentially more comfortable. It also gives them the choice of local or remote building diagnosis. The system to be demonstrated is an example of an entire wave of information based technology. It gives customers a direct entree into this entire new field.

The participants in the interviews were selected by their peers as the best in the field. The projects for the demonstrations will represent prestigious Class A buildings, chosen to attract the attention of the competitive building management industry. The managers of the pilot projects are willing to have tours through their sites for their competitors and industry associations. The industry participants have been told that the work being done for pre-commercial public-goods research, and that the findings will be widely disseminated.

\subsubsection{The Market for the Proposed Diagnostic Systems}

The market for the diagnostic system comprises suppliers of the products and services, and users of the products and services. The users are primarily building owners and property managers. There are many potential scenarios for the delivery of the products and services being explored in this project. There are three classes of suppliers.

- Utilities - First, utilities could supply this equipment and service. They are technically capable and well placed in terms of customer contacts to do this. Utilities throughout the country and around the globe are examining how to provide better information services to customers. These information services are designed to assist customers in understanding their energy use patterns and identify opportunities to lower operating costs. Many utilities are exploring how to provide better information given current metering and data analysis technology. Utilities are getting more involved in evaluating building energy performance, with services beyond one-time rebates. Some utilities are examining the business of owning and operating cooling and heating plants in which the owner would purchase heating and cooling, rather than electricity.

- ESCOs - Second, Energy Service Companies (ESCOs) may install this type of system in order to perform better diagnosis. The system is permanent and would presumably be left in the building after the ESCO completes work. Of course, given the need for permanent monitoring of buildings, this system might encourage ESCO firms to become long term partners with owners. Many ESCOs obtain much of the guaranteed energy savings from carefully managing a building, taking over control of the day-to-day operations. ESCOs are not as active in Class A office buildings as they are in other market segments because Class A operators have greater in-house staff and expertise, and are more capable of conducting analysis of new technologies.

- Equipment Manufacturers - The third supplier class is building equipment manufacturers. The environment involving building managers and equipment manufacturers is extremely complex, but there is no technical reason why such manufacturers could not provide systems of the type envisioned here. Given their presence in the building industry, and broad range of services (from energy 
management to fire-life-safety and even janitorial), control companies are in a good position to deliver advanced diagnostic systems. Many control companies have formed ESCOs, which enable them to be directly involved in whole-building energy performance analysis.

Appendix I, Market Transformation Opportunities for Diagnostic Systems in Commercial Buildings, contains a more complete discussion of the market issues. It is a stand-alone paper describing the diagnostic system and plans for Phase 2. The paper includes a summary of the Phase 1 project and specific technologies and services that might be offered by commercial firms. It also discusses a plan for Phase 2 and how the team envisions involving commercial firms in transferring the technology to the emerging marketplace following the Phase 2 demonstration.

\subsection{Task J: Plans for Phase 2 Demonstration}

\subsubsection{Purpose of Planning for Phase 2}

The purpose of this task was to develop a detailed work plan for the Phase 2 demonstration of the diagnostic system.

\subsubsection{Plans for the Phase 2 Demonstration}

The purpose of the Phase 2 demonstration is to build, deploy, and evaluate the diagnostic system described in the previous sections. Our approach is to build the system for an actual building using a flexible system architecture, and embellishing it as warranted by feedback from building owners and operators. The project is designed to be a collaborative effort involving the primary research team, plus the utilities, building owners, and managers. The specific objectives of the demonstration are:

- To save $15 \%$ of the energy used in a large commercial building by applying sophisticated monitoring and data visualization techniques with generalized rules to determine the problems in various building system and correct them.

- To develop a viable set of diagnostic tools and data sets to create a specification for a diagnostics system.

The demonstration consists of the following elements. The first task is to finalize an agreement with a building engineer and property manager to allow the system to be installed. The final custom specification will be developed and the equipment will be purchased. The equipment will then be installed and commissioned, plus the operators will be trained to download the data into the diagnostics system.

Once the system is installed we will carefully document how it is used and evaluate the data collected on site. The data will reside at the building and the research team will access it remotely using common ftp (file transfer protocol) tools. LBNL will develop a redundant data set for back-up and analysis. Baseline energy performance data will be collected for use in evaluating energy savings from changes in operations that result from using the diagnostic system. This evaluation requires recording changes made in operations and control.

The research team will develop a preliminary functional specification documenting rules and algorithms to describe the most important faults detected with the diagnostic system. The specification will include an electronic document to (a) describe rules and variables 
used for performance assessment and diagnosis, (b) identify degradation and failure modes and conditions associated with each mode, and (c) identify all ranges of variables used to categorize performance. As mentioned above, the demonstration effort will also explore methods to automate the diagnostics. The increased intelligence will take two forms: (1) more automated diagnoses and (2) the beginning of a capability of the system to be self learning (learn from experience).

Another important aspect of the demonstration is the evaluation of human factors and the ease of use of the diagnostic system. This evaluation will consider questions such as: how is the system being used, and are there major issues with the interface that inhibit the optimal use of the system? These same questions and findings will be reviewed with the peer operators and owners to obtain additional feedback on these questions from similar potential users. A series of recommendations will be implemented if possible.

Since high quality sensors are a critical element of the diagnostic system design, the demonstration will include an evaluation of the costs and benefits of data accuracy and relative value of each data point. This activity will include categorizing the data in the test system to determine which data fields were most useful and important, plus evaluate accuracy requirements for each diagnostic technique used and performance failure identified. This task will also include evaluating the life-cycle costs (first costs and maintenance costs) of high-quality, high-end sensors versus alternative, more common sensors. The demonstration will also include comparisons of the EMCS data with the diagnostics system data.

There are several strategies we will use to disseminate results from the demonstrations. The building owners directly involved in the demonstrations will be communicating with us with electronic mail. We will also set up a World-Wide-Web site on the Internet with current results. Our correspondence with them will be tracked and condensed technical updates will be circulated to a broader audience interested in tracking our progress. We will also conduct a series of technical on-site tours, workshops, and Project Advisory Committee (PAC) briefings. The technical tours will consist of bringing outside parties into the buildings to observe how the diagnostic system is deployed and operated. The workshops will be open to interested parties to allow the team to present interim results on our progress. The PAC meetings are designed to obtain more formal feedback from the advisory group. Prior to these meetings we will circulate progress reports that allow the PAC to review technical findings.

CIEE is potentially interested in diagnostic systems designed around other building systems in future phases of the project. This might include commercial thermal distribution systems, laboratories, and clean rooms. 


\section{References}

The following references were cited in the above report. This list is followed by a complete list of all references cited in each of the appendices.

Akbari, H., J.H. Eto, I. Turiel, K.E. Heinemeier, B. Lebot, B. Nordman, and L.I. Rainer. January 1989. "Integrated Estimation of Commercial Sector End-Use Load Shapes and Energy Use Intensities." LBNL Report No. 27512.

Akbari, H., Rainer, L, and Eto, J., "Integrated Estimation of Commercial Sector End-Use Load Shapes and Energy Use Intensities, Phase II," Final Report submitted to the California Energy Commission, Jan. 1991, LBNL Report No. 30401.

Akbari, H., Eto, J., Konopacki, S. , Afzal, A., Heinemeier, K., and Rainer, L., "Integrated Estimation of Commercial Sector End-Use Load Shapes and Energy Use Intensities in the PG\&E Service Area," Final Report submitted to the California Energy Commission, 1993, LBNL Report No. 34263.

Brohard. G. J., and Hernandez, G.R., "Commissioning the ACT2 Project Pilot Demonstration," Proceedings of the ACEEE 1994 Summer Study on Energy Efficiency in Buildings, Vol. 5, American Council for an Energy-Efficient Economy, Washington D.C., August 1992.

Claridge, D.E., Haberl, J., Liu, M., Houcek, J., and Athar, A., "Can You Achieve 150\% of Predicted Retrofit Savings? Is It Time for Recommissioning?, "Proceedings of the $A C E E E 1994$ Summer Study on Energy Efficiency in Buildings, Vol. 5, American Council for an Energy-Efficient Economy, Washington D.C., August 1994.

Energy User News, Vol. 20, Number 4, April 1995. The Chilton Co., Radnor PA.

Fryer, L., "Electric Chiller Buyer's Guide: Water-Cooled Centrifugal and Screw Chillers," Esource Technical Update, Feb. 1995, TU-91-1, Esource, Inc., Boulder, CO.

J.S. Haberl, T.A. Reddy, D.E. Claridge, W.D. Turner, D.L. O'Neal, and W.M. Huffington, Measuring Energy-Saving Retrofits: Experiences from the Texas LoanSTAR Program, Texas A\&M University, Oak Ridge National Laboratory Report,

ORNL/Sub/93-SP090/1, July 1995.

Herzog, P. and LaVine, L. "Identification and Quantification of the Impact of Improper Operation of Midsize Minnesota Office Buildings on Energy Use: A Seven Building Case Study," Proceedings of the ACEEE 1992 Summer Study on Energy Efficiency in Buildings, Vol. 3, American Council for an Energy-Efficient Economy, Washington D.C., August 1992.

Houghton, D., A Market Survey of Liquid Flow Meters, ESOURCE Strategic Memo, Boulder Colorado, Feb. 1996.

Houghton, $\mathrm{K}$, personal communication concerning the long-term performance of magnetic flow meter at the Minneapolis Municipal Waste Water Treatment Plant, January, 1996.

Hyvarinen, J., and R. Kohonen, Editors, "Building Optimisation and Fault Diagnosis System Concept", IEA Annex 25: Real Time Simulation of HVAC systems for Building 
Optimization, Fault Detection and Diagnosis, Technical Research Centre of Finland, Laboratory of Heating and Ventilation, BO Box 20602150 ESPOO FINLAND, October 1993.

Hyvarinen, J., and S. Karki, Editors, "Building Optimisation and Fault Diagnosis System Source Book", IEA Annex 25: Real Time Simulation of HVAC systems for Building Optimization, Fault detection and Diagnosis, Technical Research Centre of Finland, Laboratory of Heating and Ventilation, BO Box 180402044 VTT, ESPOO FINLAND, August, 1996.

Lee, Eng Lock and Hibberd, Douglas, "An Improved Method of Collection, Visualization, and Analysis of End-Use Data for Designers," Proceedings of the ACEEE 1992 Summer Study on Energy Efficiency In Buildings, Vol. 3, August 1992.

Piette, M.A., and Nordman B., " Costs and Benefits from Utility-Funded Commissioning of Energy-Efficiency Measures in 16 Buildings," ASHRAE Transactions, 1996, V. 102 Pt. 1., full report was to the Bonneville Power Administration, LBL-36448.

Piette, M.A., Diamond, R., Nordman B., de Buen O., Harris J.P., Heinemeier, K., and Janda, K. Final Report on the Energy Edge Impact Evaluation of $28 \mathrm{New}$, Low-Energy Commercial Buildings, Report to the Bonneville Power Administration, LBL-33708, February 1994.

Piette, M.A. and Riley, R., "Energy and Power Performance of New Commercial Buildings: Results and Data Issues from the BECA-CN Data Compilation, Proceedings of the $13^{\text {th }}$ Annual Energy Technology Conference, Washington D.C., March 1986, LBL Report No. 20896.

Rogers, Everett M., Diffusion of Innovation „, New York Free Press, 1983.

Waterbury, S.S., Frey, D. J., and Johnson, K.F. "Commercial Building Performance Evaluation and HVAC Diagnostics and Commissioning, "Proceedings of the ACEEE 1994 Summer Study on Energy Efficiency In Buildings, August 1994.

Yoder R. and Kaplan M. "Building Commissioning for Demand-Side Resource Acquisition Programs," Proceedings of the ACEEE 1992 Summer Study on Energy Efficiency in Buildings, Vol. 5, American Council for an Energy-Efficient Economy, Washington D.C., August 1992.

ESL Home Page, http://www-esl.tamu.edu/, 1996.

\section{Appendix A2: Commissioning}

ASHRAE, ASHRAE Guideline 1-1989, Commissioning of HVAC Systems. Atlanta; American Society for Heating, Refrigeration, and Air-Conditioning, 1989.

Claridge, D., Haberl, J., Liu, M., Houcek, J., and Athar A., "Can You Achieve 150\% of Predicted Retrofit Savings? Is it Time for Recommissioning" Proceedings from the ACEEE 1994 Summer Study on Energy Efficiency in Buildings, Vol. 5, ACEEE, Washington D.C., August 1994.

Herzog, P. and LaVine, L. "Identification and Quantification of the Impact of Improper Operation of Midsize Minnesota Office Buildings on Energy Use: A Seven Building Case Study, "Proceedings from the ACEEE 1992 Summer Study on Energy Efficiency in Buildings, Vol. 3. ACEEE, Washington D.C., August 1992. 
Piette, M.A., Diamond, R., Nordman B., de Buen O., Harris J.P., Heinemeier, K., and Janda, K. Final Report on the Energy Edge Impact Evaluation of $28 \mathrm{New}$, Low-Energy Commercial Buildings, Prepared for the Bonneville Power Administration LBL-33708, February 1994.

Piette, M.A., Nordman, B., and Greenberg, S., Commissioning of Energy-Efficiency Measures: Costs and Benefits for 16 Buildings, November 28, 1994, prepared for the Bonneville Power Administration.

Portland Energy Conservation, Inc. (PECI), "Summary Report", Proceedings of the Second National Conference on Building Commissioning, St. Petersburg, Florida, May 911, 1994. Proceedings published by PECI, Portland, Oregon.

Portland Energy Conservation, Inc. (PECI), Proceedings of the Second National Conference on Building Commissioning, Sacramento, California, May 1993, Proceedings published by PECI, Portland, Oregon.

Yoder R. and Kaplan M. "Building Commissioning for Demand Side Resource Acquisition Programs," Proceedings of the ACEEE 1992 Summer Study on Energy Efficiency in Buildings, Vol. 5, ACEEE, Washington D.C., August 1992.

\section{Appendix B: State of Diagnostic Systems and Related Technology}

Beckwith, T. G. and Roy D. Marangoni, Mechanical Measurements, 4th ed., Reading, Mass. : Addison-Wesley Pub. Co., [1990].

Bertino, M. and M.T.Ozsu eds., Distributed And Parallel Data Base Object Management, Kluwer, 1994.

Blanc, S.L., “Automated Diagnostics Scoping Study”, Report \#008.1-94.8, Pacific Gas and Electric Company, 1993.

Brambley, M.R., Conference Summary: PG\&E/DOE Workshop on Building Operation, Boulder Colorado 1994.

Bratko, I, Prolog Programming for Artificial Intelligence, Addison Wesley, 1990.

Haberl, J.S., T.A. Reddy, D.E. Claridge, W.D. Turner, D.L. O'Neal, and W.M. Huffington, " Measuring Energy-Saving Retrofits: Experiences from the Texas LoanSTAR Program" Texas A\&M University, Oak Ridge National Laboratory Report, ORNL/Sub/93-SP090/1, July 1995.

Haberl, J.S., R.M. Nelson, and C.C. Culp eds., "The use of Artificial Intelligence in Building Systems", ASHRAE Report 1995.

Haberl et. al. http://www-esl.tamu.edu/

Haykin Simon S, Neural Networks, A Comprehensive Foundation, Macmillan, New York, 1994.

Hertz, J, A. Krogh and R.G. Palmer, Introduction To The Theory Of Neural Computation, Addison Wesley, 1991. 
Hush D.R. and W.G. Horne, Progress in Supervised Neural Networks, IEEE Signal Processing Magazine, v. 10, no. 1, pp 8-39, 1993.

Hyvarinen, J., and R. Kohonen, "Building Optimisation and Fault Diagnosis System Concept", IEA Annex 25: Real Time Simulation Of HVAC Systems For Building Optimization, Fault Detection And Diagnosis, Technical Research Centre of Finland, Laboratory of Heating and Ventilation, BO Box 206 (Lampomiehenkuja 3) 02150 ESPOO FINLAND, October 1993.

Kemper, A.H., Object-Oriented Data Base Management: Applications In Engineering And Computer Science, Prentice Hall, 1994.

Kosko, B., Neural Networks and Fuzzy Systems, Prentice Hall, 1991.

Kreider, J.F., and J.S. Haberl, "Predicting Hourly Building Energy Use: The Great Energy Predictor Shootout” ASHRAE Technical Data Bulletin, vol. 10, no. 5, June 1994.

Lee, J.P., And G.G. Grindstein Eds., Database Issues For Data Visualization, IEEE Visualization 1993 Workshop, Springer Verlag, 1994.

Lee, Eng Lock and Hibberd, Douglas, "An Improved Method of Collection, Visualization, and Analysis of End-Use Data for Designers", Proceedings of the ACEEE 1992 Summer Study on Energy Efficiency In Buildings, Vol. 3, August 1992.

Quadrell R.W. and T. A. Lash, "Automated Diagnostics Scoping Study: Final Report", Report PNL-9808-UC350, Pacific Northwest Laboratory, June 1994.

Sebald, A. V. and , "Application of Neural and Fuzzy systems to smart buildings", Proceedings, 1993 CIEE annual Meeting, Also: Final Report, CIEE Exploratory Project On The Use Of Neural Nets And Fuzzy Logic In Buildings, 1993

Waterbury, S.S.., Frey, D. J., and Johnson, K.F. "Commercial Building Performance Evaluation and HVAC Diagnostics and Commissioning, "Proceedings of the ACEEE 1994 Summer Study on Energy Efficiency In Buildings, August 1.994.

Willard, D.E., Applications of Range query theory to relational data base join and selection operations, Journal Of Computer And System Sciences, vol. 52, No. 1, 1996, pp 157-169.

Yager R.R., ed., Fuzzy Sets And Applications: Selected Papers By L. Zadeh, Wiley Interscience, 1991.

\section{Appendix B1: Process Monitoring And Diagnostic Techniques Used In Process Control}

Dhurjati, P. S. (ed.) (1992). Proc. IFAC Sympos. on On-Line Fault Detection and Supervision in the Chemical Process Industries, Newark, DE.

Dubois, D., (1993). Fuzzy Sets: A survey of engineering applications. Comput. \& Chem. Eng., 17, S373-380.

Fasolo, P.S. and D. E. Seborg. An SQC approach to monitoring and fault detection in HVAC control systems. Proc. 1994 Amer. Control Conf. pp. 3055-59, Baltimore (July, 1994). 
Fasolo, P.S. and D. E. Seborg. Monitoring and fault detection for an HVAC control system. Proc. IFAC ADCHEM Sympos., pp. 537-542, Kyoto, Japan (May, 1994).

Frank, P.M. (1990). Fault diagnosis in dynamic systems using analytical and knowledgebased redundancy -- a survey and some new results. Automatica, 26, 459-474.

MacGregor, J. F. (1988). On-line statistical process control. Chem. Eng. Progr., 84 (10), 21-31.

MacGregor, J.F. (1994). Statistical process control of multivariable processes. Preprints of the IFAC ADCHEM '94 Sympos., 215-224, Kyoto, Japan, May, 1994.

Patton, R., P. Frank and R. Clark (ed.), (1989). Fault Diagnosis In Dynamic Systems, Prentice Hall, NY.

Pottmann, M. \& D.E. Seborg (1992a). Identification of nonlinear processes using reciprocal multiquadric functions. J. Process Control, 2, 189-203.

Pottmann, M. \& D.E. Seborg (1992b). Identification of nonlinear processes incorporating a priori physical knowledge. Paper presented at the 1992 AIChE Annual Meeting, Miami Beach, FL, Nov., 1992.

Samdani, G. (1992). Managing knowledge. Chem. Eng., 99 (4), 5.

Samdani, G. and K. Fouhy (1992). Smart software. Chem. Eng., 99 (4), 30-33.

Samdani, G., K. Fouhy, and S. Moore (1993). Fuzzy logic: more than a play on words. Chem. Eng., 100 (2), 30-33.

Seborg, D.E., T.F. Edgar, and D.A. Mellichamp (1989). Process Dynamics and Control, John Wiley \& Sons, NY.

Stephanopolous, G. and C. Han (1994). Intelligent systems in process engineering: a review. Preprints of the 5th Internat. Sympos. on Process Systems Eng. (PSE 94), 13391366, Kyongju, Korea, June, 1994.

Thompson, L. and G. Mertz (1993). Real-time expert system implementation at Monsanto-Krummrich. Automatica, 29, 1177-83.

Wadsworth, H.M., K.S. Stephens, and A.B. Godfrey (1986). Modern Methods for Quality Control and Improvement. John Wiley, NY.

Yamamoto, S.. and I. Hashimoto (1991). The view from Japanese industry. in Chemical Process Control - CPC IV, Y. Arkun \& W.H. Ray (ed.), AIChE, NY.

\section{Appendix B2: EMCS}

ASHRAE. 1987. ANSI/ASHRAE Standard 114-1986--Energy Management Control Systems Instrumentation. American Society of Heating, Refrigeration and AirConditioning Engineers, Atlanta, GA.

Barrington. 1989. LanSTAR Model SC-LS-1 User's Manual. Barrington Systems, San Carlos CA.

EIA 1992. Annual Energy Review 1991. Energy Information Administration, U.S. DOE. 
EPRI. 1992. Survey of End-Use Metering Equipment, Sensors, and Designers/Installers. EPRI TR-100745. Electric Power Research Institute, Palo Alto, CA.

EPRI. 1986. Energy Management Systems for Commercial Buildings. EPRI EM-4195. Electric Power Research Institute, Palo Alto, CA.

EUN. 1994. "EUN Product Guides: Building Automation Systems." Energy User News Magazine. October, pp. 50,51.

EUN. 1993. "New R\&D Consortium to Test Interoperability of BACNet Products." Energy User News Magazine. November, pp. 1,25. Greely, K.M., J.P. Harris, A.M. Hatcher. 1990. Measured Savings and Cost-Effectiveness of Conservation Retrofits in Commercial Buildings. LBL-27568, Vol. 1 and 2. Lawrence Berkeley Laboratory, Berkeley CA.

Gunterman, A.E. 1982. "Energy Management Systems: Are They Cost Effective?" Heating/Piping/Air Conditioning. September, pp. 102-116.

Johnson Controls. 1991. Metasys Product Literature. Johnson Controls, Inc. Milwaukee WI.

Kao, J.Y, and E.T. Pierce. 1983. "Sensor Errors: Their Effects on Building Energy Consumption." ASHRAE Journal. December, pp. 42-45. American Society of Heating, Refrigeration and Air-Conditioning Engineers, Atlanta, GA.

Kele. 20/20 Interface Products Catalog. Kele \& Associates, Memphis TN.

Landis \& Gyr Powers. 1992. System 600 Product Information. Landis \& Gyr Powers, Inc., Buffalo Grove IL.

Lambert. 1989. Product Information: Data-Trap. Lambert Engineering, Inc. Bend, $\mathrm{OR}$.

Microsoft. 1991. Microsoft Windows. Microsoft Development Corp. Redmond WA.

NCAEC. 1987. Assessment of Commercial Load Management Opportunities Using Energy Management Systems. North Carolina Alternative Energy Corporation.

OSI. 1991. Product Information: power transducers. Ohio Semitronics, Inc. Columbus $\mathrm{OH}$.

Synergistic Control Systems Inc. 1989. Technical Specification for the Model C180 Survey Meter/Recorder. New Orleans LA.

Teletrol. 1991. Integrator Product Information. Teletrol Systems, Inc. Manchester, NH.

Appendix C: Technical Report On Relevant Sensor Issues

Hartman, Thomas B., Direct Digital Controls For HVAC Systems, McGraw Hill, 1993.

Morris, A.S., Principles of Measurement and Instrumentation, Prentice Hall, London, 1993. 
Papoulis, A., Probability, Random Variables, And Stochastic Processes, New York, McGraw-Hill, 1965.“

\section{Appendix F: Technical Report on Failure Mode Analysis}

Akbari, H., J.H. Eto, I. Turiel, K.E. Heinemeier, B. Lebot, B. Nordman, and L.I. Rainer. January 1989. "Integrated Estimation of Commercial Sector End-Use Load Shapes and Energy Use Intensities." LBNL Report No. 27512.

ASHRAE (American Society of Heating, Refrigerating, and Air-Conditioning Engineers), Standard 105-1984: Standard Methods for Measuring and Expressing Building Energy Performance. Atlanta, Georgia, Reaffirmed, 1990.

ASHRAE, "Cooling Towers," 1992 Heating, Ventilating, and Air-Conditioning Systems and Equipment Handbook. "Chapter 37, Atlanta, Georgia

Bernier, M.A. 1994. "Cooling Tower Performance: Theory and Experiments." ASHRAE Transactions, \#3794, Vol. 100, Part 2

Buhl, W.F., Erdem, A.E., Winkelmann, F.C., and Sowell, E.F., "Recent Improvements in SPARK; Strong Component Decomposition, Multivalued Objects, and Graphical Interface," Proceedings Building Simulation 1993, the International Building Performance Simulation Association, Adelaide, Australia, August, 1993, LBNL-33906.

Energy User News, Vol. 20, Number 4, April 1995. The Chilton Co., Radnor PA.

Houghton, D.J., Bishop, R.C., Lovins, A.B., Stickney, B.L., Newcomb, J.J., Shepard, M., and Davids, B.J., The State of the Art: Space Cooling and Air Handling, proprietary technical report from COMPETITEK, Boulder, Colorado, August 1992.

Kintner-Meyer, M., and A.F. Emery, "Cost-Optimal Design for Cooling Towers," ASHRAE Journal, April 1995.

Koran, William, E "Expanding the Scope of Commissioning: Monitoring Shows the Benefits," ASHRAE Transactions, Vol. 100, Pt. 1, 1994.

Lee, Eng Lock and Hibberd, Douglas, "An Improved Method of Collection, Visualization, and Analysis of End-Use Data for Designers," Proceedings of the ACEEE 1992 Summer Study on Energy Efficiency In Buildings, August 1992.

Lee, Eng Lock and Andrew Chiang, Electric Eye Case Studies, Technical report, SuperSymmetry, Singapore, 1994.

Liu, M, Houcek, J., Ather, A., Reddy, A., Claridge, D., and Haberl, J., "Identifying and Implementing Improved Operation and Maintenance Measures in Texas LoanSTAR Buildings, Proceedings of the ACEEE 1994 Summer Study on Energy Efficiency In Buildings, August 1994.

Hensley, J.C.(editor), Cooling Tower Fundamentals, The Marley Cooling Tower Company, Second Edition, 1985.

Piette, M.A. and Riley, R., "Energy and Power Performance of New Commercial Buildings: Results and Data Issues from the BECA-CN Data Compilation, Proceedings of the $13^{\text {th }}$ Annual Energy Technology Conference, Washington D.C., March 1986, LBL Report No. 20896.

Piette, M.A., Nordman, B. deBuen, O., and Diamond, R., "Findings from a Low-Energy New Commercial Buildings Research and Demonstration Project," Energy - The International Journal, Vol. 20, No. 6, pp. 471-482, 1995a.

Piette, M.A., Nordman, B., and Greenberg, S., "Commissioning of Energy-Efficiency Measures: Costs and Benefits for 16 Building," LBL Report No. 36448, April, 1995 b.

Shelton, S.V., and C.T. Joyce. 1991. "Cooling Tower Optimization for Centrifugal Chillers." ASHRAE Journal, June 1991. 
US Dept. of Energy, Energy Information Administration, Commercial Buildings Consumption and Expenditures, DOE/EIA-0318(92) April 1995.

Waterbury, S.S.., Frey, D. J., and Johnson, K.F. "Commercial Building Performance Evaluation and HVAC Diagnostics and Commissioning," Proceedings of the ACEEE 1994 Summer Study on Energy Efficiency In Buildings, August 1994.

Zhang, Z.J. 1992. "Keep your Cooling Tower?", ASHRAE Journal, June 1992.

\section{Appendix H: Technical Report On Contact With Manufacturers}

Smith D. K. and R. C. Alexander, Fumbling The Future : How Xerox Invented, Then

Ignored, The First Personal Computer, 1st ed. New York: W. Morrow, c1988.

\section{Appendix I: Market Transformation Opportunities For Diagnostic Systems In Commercial Buildings}

Rogers, Everett M., Diffusion Of Innovations., New York, Free Press of Glencoe, 1962. 


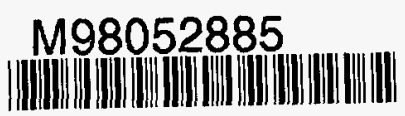

Report Number (14) $L$ BNL -40512

Publ. Date (11)

Sponsor Code (18)

UC Category (19)

99713.

180q/qq, XF

(19) $|1 C-1600, D D E| E R$ 